\title{
Estructura de la corteza cerebral. Organización intrínseca y análisis comparativo del neocórtex
}

\author{
F. Valverde
}

\author{
STRUCTURE OF THE CEREBRAL CORTEX. \\ INTRINSEC ORGANIZATION AND COMPARATIVE ANALYSIS OF THE NEOCORTEX
}

\begin{abstract}
Summary. We review our present knowledge on the intrinsic organization of the neocortex based on studies carried out with the Golgi method in several mammalian species. An outline is presented on certain general aspects of the termination of specific afferent fibers in layer IV in insectivora, rodents, carnivora and primates. The principal components of the cerebral cortex have been classified in two broad types: pyramidal cells, which account for nearly $70 \%$ of the total population, and intrinsic neurons. We review different morphological characteristics of pyramidal cells and intrinsic neurons with a full description of cell varieties, dendritic morphology and several aspects of synaptic connectivity of intrinsic neurons in comparison between different species. Special attention has been paid to the description of spinous stellate cells which seems unique for a given animal species. We have reviewed intrinsic cortical circuits linking several neocortical layers, the distribution of dendritic plexuses, and the excitatory and inhibitory synaptic connections established between various neuronal categories. We finally review modern concepts of functional neocortical architecture based on the modular organization of the cerebral cortex, concluding that the cerebral cortex is rather uniform at en elementary level but the differences appear substantial when the comparison is made between different species. [REV NEUROL 2002; 34: 758-80] Key words. Cerebral cortex. Cortical afferent fibers. Intrinsic cells. Modular organization. Pyramidal cells.
\end{abstract}

\section{INTRODUCCIÓN}

La corteza cerebral de mamíferos está representada por una lámina de sustancia gris que cubre los hemisferios cerebrales. Es una estructura extremadamente compleja en la que los distintos órganos sensoriales aparecen representados en determinadas áreas o zonas conocidas como áreas sensoriales primarias. Desde el sentido del olfato hasta el de la visión, cada modalidad sensorial posee su propio territorio cortical, el cual mantiene una localización relativamente constante en todos los mamíferos. Además de estas áreas sensoriales primarias, la corteza cerebral posee múltiples áreas somáticas secundarias, de asociación y motoras, en las que los diferentes sistemas aferentes corticales y de asociación son finalmente elaborados en complejas respuestas de aprendizaje, memoria y comportamiento. La organización de esta estructura que, desde nuestra perspectiva humana, adquiere su complejidad máxima en el hombre, es el resultado de un lento proceso evolutivo que pudo haber comenzado hace 150 millones de años en la supuesta transición reptil-mamífero [146].

Puede afirmarse que los estudios sistemáticos de la corteza cerebral comenzaron con las investigaciones de Maynert [210] y Betz [15], quienes establecieron el hecho fundamental de que la

Recibido: 13.02.02. Aceptado tras revisión externa sinmodificaciones: 26.02.02.

Profesor de Investigación. Instituto de Neurobiología Santiago Ramón y Cajal (CSIC). Madrid, España.

Correspondencia: Prof. Facundo Valverde. Instituto Cajal (CSIC). Avenida del Dr. Arce, 37. E-28002 Madrid. Fax: +3491 5854754. E-mail: fvalverde@ cajal.csic.es

Agradecimientos. Este estudio ha sido subvencionado por los Proyectos de Investigación MEC PB 91-0066 y MCYT PB1996-0813 del Programa Nacional de Promoción General del Conocimiento. Nuestros trabajos anteriores, referidos en esta revisión, estuvieron financiados por USPHS TW-00202, CAICYT 3344/79 y 1329/81, así como por Ayudas de Investigación de las Fundaciones Juan March y Eugenio Rodríguez Pascual. Nuestro agradecimiento al doctor Torsten $N$. Wiesel (The Rockefeller University) por su autorización para reproducir la figura 12 de este trabajo, así como a los doctores Juan A. de Carlos y Laura López-Mascaraque por su inestimable ayuda y compañerismo. Nuestra gratitud a Concepción Bailón y Carmen Hernández por su paciencia en la obtención de las imágenes que ilustran este trabajo.

(c) 2002, REVISTA DE NEUROLOGÍA corteza cerebral presenta una organización celular en distintas capas. Bevan Lewis sugirió en 1878 [180] un plan de estratificación de la corteza cerebral en seis capas diferentes, plan que ha permanecido hasta la actualidad. Basado en este plan estructural, la corteza cerebral ha sido dividida en dos tipos fundamentales: el isocortex y el allocortex de Brodmann [24] y Cécile y Oskar Vogt [332]. El isocortex o neocórtex corresponde a aquella parte de la corteza en la que siempre puede reconocerse la estratificación en seis capas, mientras que el allocortex, representado por el archicórtex (hipocampo y fascia detata) y palecórtex (corteza olfativa propiamente dicha), exhiben una estructura laminar simple compuesta por tres capas. Ambos tipos corticales están más o menos separados por cierto número de áreas paracorticales que han sido objeto de gran interés en el estudio de la evolución cortical [272]. Los estudios de la corteza cerebral, basados en los anteriores conceptos, dominaron gran parte de las investigaciones llevadas a cabo a principios del s. Xx, en donde el análisis exclusivamente citoarquitectónico obtenido con el método de Nissl dio por resultado la descripción de numerosas parcelaciones corticales carentes, en la mayoría de los casos, de significado funcional y que, como hemos señalado en otro lugar [325], se nos muestran como 'mapas de carreteras sin carreteras'. Fue precisamente Ramón y Cajal [254] quien, empleando el método de Golgi, realizó una descripción completa de la organización intrínseca de la corteza cerebral del hombre y vertebrados, mostrando la estructura y conexiones de los distintos tipos neuronales, su organización dendrítica y axonal, y la disposición de los plexos de fibras aferentes y eferentes.

Las seis capas fundamentales del isocórtex temporoparietoccipital son: capa I o capa plexiforme externa, capas II y III o de células piramidales pequeñas y medianas, respectivamente (la capa II también es conocida como capa granular externa debido al reducido tamaño, en algunos mamíferos, de sus componentes celulares), capa IV o capa granular interna, capa V o de las grandes células piramidales, y capa VI o capa de células fusiformes. Desde un punto de vista puramente descriptivo, la capa I contiene escasas células, numerosas fibras horizontales y los ramajes terminales de las células piramidales de capas subyacentes, las capas II y III albergan una gradación de células piramidales de ta- 
maño pequeño a mediano, la capa IV contiene células piramidales de tamaño semejante a las de la capa II y variedades de pequeñas células estrelladas. Esta capa está ausente en la corteza motora y en algunas zonas de la corteza en insectívoros, y es el estrato fundamental de ramificación de las fibras aferentes corticales. La capa V o ganglionar aloja grandes células piramidales, y en la capa VI habitan variedades de células de forma irregular, fusiformes o polimorfas. Esta estratificación simplista, que se adhiere rígidamente al esquema de las seis capas, ha dado lugar a numerosas discrepancias, ya que se demostró que estaba basada en conceptos embriológicos erróneos [186,187], pero ha servido, y sirve, para estudiar la organización intrínseca de la corteza cerebral, catalogar variedades neuronales específicas de cada capa, sistematizar la distribución de fibras aferentes y conexiones intrínsecas y, lo que es más importante, establecer el marco adecuado para realizar estudios comparativos entre distintos mamíferos.

Existen numerosas características estructurales que se repiten en todas las áreas corticales de todos los mamíferos; sin embargo, como enérgicamente formulara Lorente de Nó en su clásico capítulo de la Fisiología de Fulton [187], muchas regiones corticales poseen rasgos estructurales específicos que hacen imposible que la descripción de un patrón estructural único sea aplicable a toda la corteza, a menos que se recurra a una simplificación extrema. La corteza cerebral contiene, aparte de células neurogliales y vasos, células nerviosas o neuronas y fibras nerviosas organizadas en capas paralelas. Cada capa tiene su propia individualidad, dada por variedades celulares específicas y por sus conexiones, pero ha de señalarse que estas capas no operan de forma aislada: los elementos que las caracterizan están íntimamente relacionados con los componentes de las otras capas corticales, siendo ésta la filosofía sobre la que se han desarrollado modernos conceptos de operación modular de la corteza, la cual es contemplada como una organización funcional de grupos celulares verticalmente ensamblados en torno a un eje central representado por fibras aferentes corticales [71,187,302-304].

Esta revisión describe el estado actual de nuestros conocimientos sobre la organización estructural del neocórtex en distintos mamíferos, y está basada en nuestras observaciones realizadas durante los últimos cuarenta años sobre una colección de más de 2.000 cerebros teñidos por el método de Golgi en distintas variedades de mamíferos, desde insectívoros hasta primates, con un interés particular en la corteza visual, que ha sido nuestro principal objeto de estudio. Se describirán en primer lugar la distribución y caracterización de las fibras aferentes talamocorticales específicas; en segundo lugar, se revisarán distintos tipos de células intrínsecas y aquellos sobre los que estas fibras aferentes realizan sus contactos sinápticos; conocida esta estructura básica se revisarán, en tercer lugar, detalles sobre la conectividad intrínseca de la corteza; en cuarto lugar se describirán aspectos fundamentales de su organización columnar y, finalmente, se realizará una aproximación a la posible evolución de la corteza cerebral desde el punto de vista de la anatomía comparada.

\section{FIBRAS AFERENTES CORTICALES Aspectos generales}

Las áreas sensoriales primarias del neocórtex (visual, somatosensorial, acústica) reciben sus principales aferentes corticales de los correspondientes órganos sensoriales a través de estaciones de relevo en núcleos talámicos específicos. Estas fibras aferentes son conocidas desde Lorente de Nó [187] como 'aferentes corti- cales específicos', y de ellos el mejor conocido corresponde al sistema de fibras aferentes a la corteza visual primaria o área 17 procedente del núcleo geniculado lateral del tálamo. Ramón y Cajal [254] reconoció estas fibras en la corteza visual humana y desde entonces se han descrito en varios estudios clásicos $[185,187,228,229,246]$. Investigaciones llevadas a cabo con técnicas de degeneración experimental [36,100,134,190,345] demostraron que la distribución de la degeneración terminal, tras lesiones en el núcleo geniculado lateral, coincide con las zonas ocupadas por las ramificaciones de fibras aferentes corticales observadas con el método de Golgi en todos los mamíferos estudiados, desde insectívoros a primates [310,311,314]. Estudios más recientes, usando técnicas de autorradiografía y degeneración [95,111, 118,120, $172,226,239,257,260,266,348]$, así como inyecciones intraaxonales con el trazador enzimático HRP (peroxidasa de rábano) de estas fibras [18,38,82,88,93,105,106,137,193,201,202,221], igualmente confirmaron detalles obtenidos en observaciones previas realizadas con el método de Golgi, ampliando considerablemente nuestro conocimiento de las diferentes características con relación a su distribución laminar, así como distintos aspectos sobre la arquitectura funcional de la corteza cerebral.

Además de estas fibras aferentes específicas, la corteza cerebral recibe otro tipo de fibras procedentes de la propia corteza (fibras de asociación corticocorticales y callosas), así como de otros núcleos talámicos y, por supuesto, de otros centros subcorticales. Siguiendo la terminología de Lorente de Nó [187], algunas de estas fibras son conocidas como 'fibras aferentes corticales inespecíficas', denominación no muy afortunada, pero que fue introducida por oposición al concepto de fibras 'específicas'. Estas fibras inervarían varias áreas corticales en donde se distribuirían en varias capas corticales, entre ellas la capa I, y se las ha considerado procedentes de los núcleos intralaminares del tálamo. En una serie de estudios ya antiguos, se demostró que estos núcleos mostraron degeneración retrógrada grave tras practicar lesiones en extensas zonas de la corteza cerebral [168,222,232]. A este sistema de fibras se le dio considerable importancia al demostrar que los núcleos reticulares del tálamo, de donde se supone que proceden, serían los responsables de iniciar la respuesta sincronizada de reclutamiento de la corteza [144,214,215].

Las fibras aferentes de asociación corticocorticales y callosas terminan prácticamente en todas las áreas y capas corticales, aunque especialmente se han descrito más abundantes en las capas II y III. La terminación de fibras callosas se ha estudiado en varias áreas corticales y en diversos mamíferos [33,48,142,339], si bien su caracterización con el método de Golgi no es convincente, pues estas fibras, así como otras provenientes de distintos centros subcorticales, sólo pueden trazarse tras lesiones experimentales o empleando distintos trazadores específicos, en donde se demuestra su terminación sobre dendritas apicales y basales de células piramidales tanto superficiales como profundas [33,48,56]. En lo que sí parecen estar de acuerdo todos estos estudios es en que existe una gran variabilidad con relación a las regiones corticales inervadas y al número y proporción de sinapsis que forman los distintos sistema aferentes de esta naturaleza.

\section{Aferentes corticales específicos}

En insectívoros el aspecto de ramificación de fibras talamocorticales es muy simple. En nuestras preparaciones teñidas por el método de Golgi, en el erizo (Erinaceus europaeus) las fibras aferentes a la región occipital (área visual) penetran en la corteza desde la sustancia blanca siguiendo un curso oblicuo y desarrollando 
ramificaciones terminales en abanico, que en conjunto forman un plexo en niveles corticales medios (en insectívoros no existe una capa IV claramente definida). Estas arborizaciones terminales probablemente realizan contactos sinápticos con grandes células piramidales de las capas II a V, células piramidales que probablemente representan las dianas para estas fibras talámicas (Fig. 1a, Faf). En el erizo se ha descrito que las fibras geniculocorticales finalizan en las capas III y VI, y que tienen cierto grado de organización topográfica [111]. En este animal también se ha descrito una proyección densa a la capa I de la corteza, similar a la descrita en roedores, que tiene su origen en el núcleo ventromedial del tálamo [111,120, 261]. Esta proyección de núcleos talámicos específicos a la capa I de la corteza posee el máximo interés desde el punto de vista de la anatomía comparada. Hemos descrito en el erizo (Fig. 1b, Fpn) un sistema de fibras gruesas que, procedentes de la sustancia blanca, ascienden a la capa I en pequeños fascículos en donde forman extensas arborizaciones en las áreas somatosensorial y visual [320,326,327]. La existencia de proyecciones de núcleos talámicos específicos a la capa I de la corteza en insectívoros aparece en todo semejante al plan de organización fundamental encontrado en el allocortex, en donde las fibras aferentes corticales están integradas por sistemas de fibras tangenciales que circulan en los estratos más superficiales de la corteza, como ocurre en la corteza olfativa [320,329], y que a su vez nos recuerdan la organización primordial del pallium cortical en anfibios y reptiles [28,224].

En roedores las fibras específicas talamocorticales pueden ser reconocidas por su morfología, forma de ramificación y distribución. Lorente de Nó [185] estudió con el método de Golgi la terminación de fibras aferentes corticales en la capa IV, en el ratón, sin especificar su origen, en donde contribuyen a delimitar determinadas estructuras que él denominó 'glomérulos', y que hoy conocemos como ‘barriles' (representación cortical de las vibrisas o pelos táctiles del hocico), específicos en la corteza somatosensorial de Roedores [335,358]. En nuestros estudios sobre la corteza visual en el ratón realizados con el método de Golgi habíamos observado que se trata de fibras gruesas que ascienden oblicuamente desde la sustancia blanca formando grupos compactos de ramificaciones terminales distribuidas fundamentalmente en la capa IV y parte baja de la capa III [330]. En estas capas, las fibras terminales están provistas de botones en passant y dilataciones terminales, presumiblemente de carácter sináptico (Fig. 2a, Faf). Durante su ascenso desde la sustancia blanca, algunas de estas fibras abandonan un número reducido de colaterales en la capa VI y no es infrecuente encon-

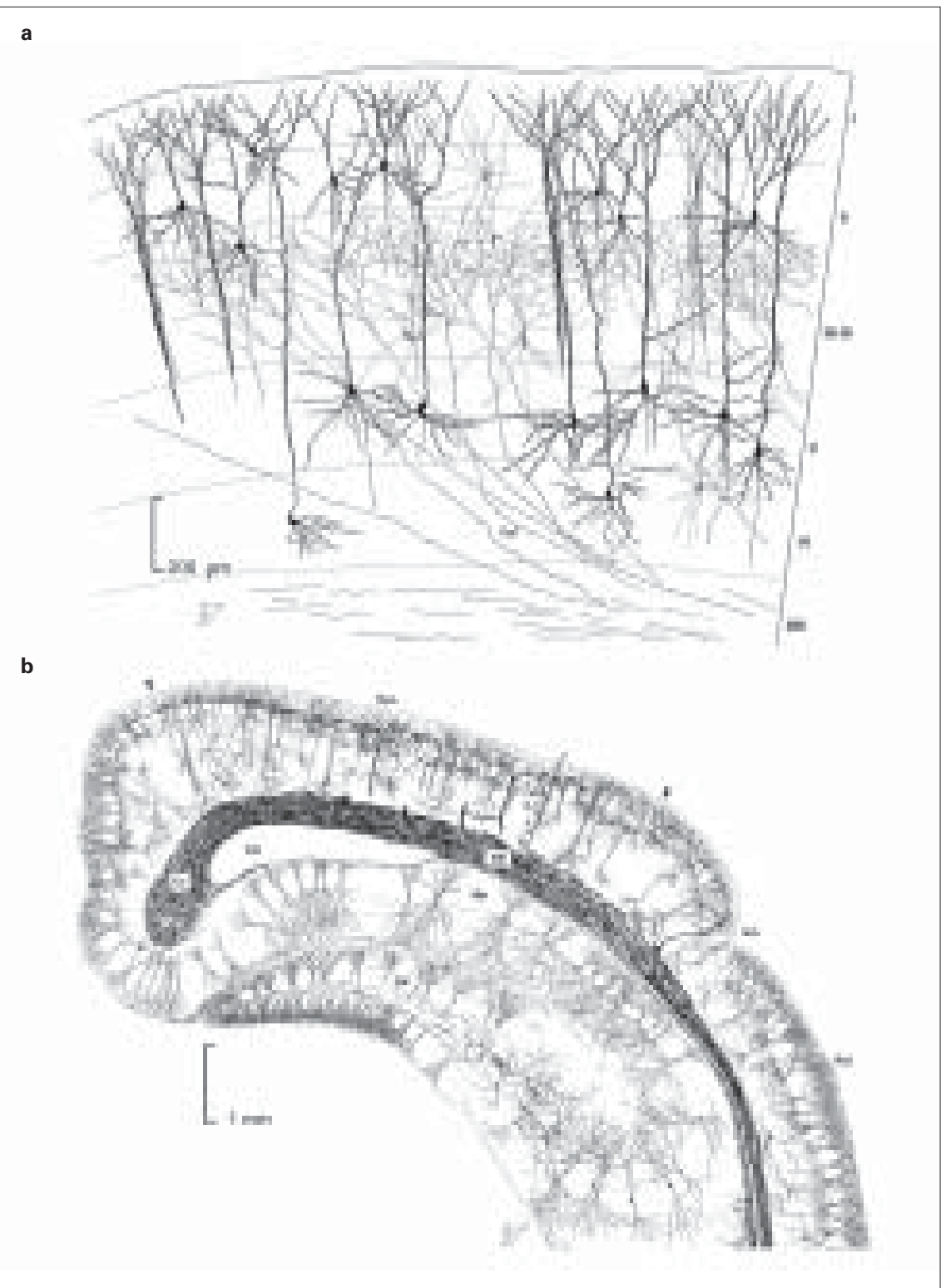

Figura 1. a) Corte sagital cercano al polo occipital del cerebro del erizo (Erinaceus europaeus) que muestra los límites de las distintas capas corticales y variedades de células piramidales superficiales y profundas. Fibras aferentes (Faf) ascienden oblicuamente desde la sustancia blanca (SB) y se ramifican en las capas medias de la corteza (III-IV). Método de Golgi. Dibujo a la cámara clara. Tomada de [318] y reproducida con autorización de Elsevier; b) Corte transversal del cerebro del erizo (Erinaceus europaeus) a nivel de la zona visual (Rpo). El corte incluye parte del hipocampo (Hip) y fascia dentata $(\mathrm{Gd})$. El neocórtex se extiende entre las dos cabezas de flecha. Fibras procedentes de la sustancia blanca (SB) forman series de haces compactos (Fpn) que ascienden y circulan por surco rinal; Vel: ventrículo lateral. Método de Golgi. Dibujo a la cámara clara. Tomada de [327] y reproducida con autorización de Springer.

trar fibras aisladas que pueden alcanzar la capa I. Esta morfología es enteramente similar a la descrita en la corteza visual del hámster tras marcaje individual de fibras con HRP en la radiación óptica [221] y por analogía, a las fibras aferentes específicas descritas en la corteza somatosensorial en la rata [145].

En este último animal, empleando métodos de autorradiografía y técnicas de degeneración axonal [98,260,275], así como mediante estudios por estimulación eléctrica [21], se ha demostrado que las fibras procedentes del núcleo geniculado lateral proyectan exclusivamente a las capas IV y VI del área 17. Estos 


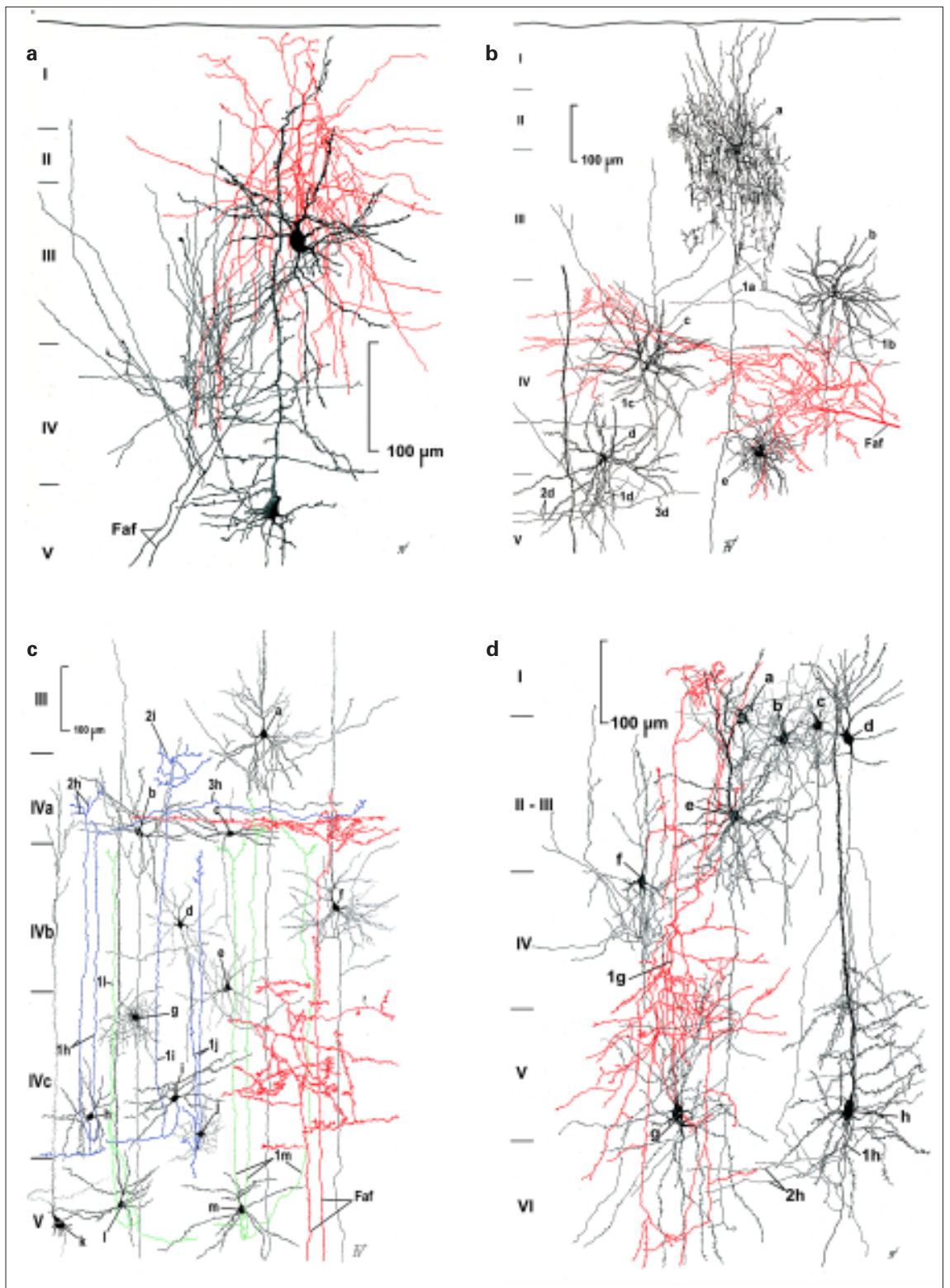

Figura 2. A. Corte transversal que muestra la distribución de las fibras aferentes específicas (Faf) en la corteza visual del ratón de 10 días. La imagen reproduce una célula piramidal de la capa $\vee$ y una célula cuyo axon (en rojo) se distribuye en las capas superficiales. Método de Golgi. Tomada de [330] y reproducida con autorización de Springer. B. Corte transversal de la corteza visual del gato de un mes que muestra la distribución de fibras aferentes específicas (Faf), una célula en candelabro (a), células estrelladas con espinas en la capa IV (b-d), y una célula en ovillo (e). Método de Golgi. C. Corte transversal de la corteza visual del mono adulto (Macaca rhesus) que muestra fibras aferentes específicas distribuidas en las capas IVa y IVc (Faf), y distintas variedades de células piramidales (a, $f, k, l, m)$, células estrelladas de la capa IVa $(b, c)$, una célula en ovillo $(g)$ y tipos de células estrelladas con espinas (d, e, h-j). Método de Golgi. Tomadas de [76] y reproducidas con autorización de Elsevier. D. Corte transversal que muestra distintas variedades celulares en la corteza visual del ratón de 11 días. Células piramidales superficiales (a-e), medianas (f) y profundas (h) acompañadas de una célula de axon ascendente ( $g$, axon en rojo). Método de Golgi. En estas reproducciones, los axones y sus colaterales están numerados, seguidos de la letra correspondiente a la célula de la cual se originan (p. ej., 3d es una colateral de la rama principal del axon, $1 d$, procedente de la célula d). Dibujos a la cámara clara. Tomada de [316] y reproducida con autorización de Chapman and Hall.

resultados son similares a los obtenidos por los autores citados en el gato, sugiriendo, además, que las fibras que terminan en la capa VI son probablemente colaterales de las fibras aferentes principales que ascienden hasta la capa IV.

Nuestras observaciones en el gato (carnívoros) utilizando el método de Golgi para el estudio de las fibras aferentes corticales fueron notablemente reveladoras, gracias al uso de animales jóvenes, en donde la mielinización de fibras aún no es completa [76,320]. En la corteza visual, estas fibras siguen un curso casi horizontal y en muchos casos se dividen en varias ramas, lo que indica que el área cubierta por una sola fibra es bastante extensa (Fig. 2b, Faf). En la capa IV estas fibras dan origen, por repetidas subdivisiones, a plexos terminales que aparecen en grupos aislados, por lo que se sugirió que esta distribución podría corresponder al aspecto de distribución periódica descrito tras inyecciones con HRP en fibras aferentes caracterizadas fisiológicamente [201]. La capa IV en la corteza visual (área 17) del gato ha sido subdividida en dos mitades aproximadamente, designadas como IVa y IVb [195,228,230].

La morfología y distribución laminar de las fibras aferentes a la corteza visual del gato se ha estudiado de forma muy precisa tras inyecciones de HRP en la radiación óptica [82] o bien mediante inyecciones en axones individuales caracterizados fisiológicamente [105]. Estos estudios demostraron que existen al menos dos tipos diferentes de fibras geniculocorticales que alcanzan la capa IV; estos tipos corresponden a las células X e Y del núcleo geniculado lateral. En este punto mencionaremos que el sistema de fibras geniculocorticales está organizado fisiológicamente en tres canales distintos, correspondientes a los sistemas X, Y y W, sobre el que existen detalladas revisiones, tanto en carnívoros como en primates [29,31,201,294], acerca de éste y otros aspectos fisiológicos de la vía retinogeniculocortical, pero cuya descripción se escapa del propósito de esta revisión. Bástenos, pues, mencionar que numerosos estudios sugieren la existencia de casi una completa segregación laminar de los distintos tipos de fibras geniculocorticales; los catalogados como aferentes de tipo Y terminan principalmente en la parte alta de la capa IV y parte baja de la capa III, mientras que los designados como aferentes de tipo $\mathrm{X}$ finalizan en la parte baja de la capa IV [27,105,113, 171,177,212]. No obstante, esta segregación tan precisa ha sido cuestionada por otros investigadores $[80,81,92,93$, $137,138,201]$, aunque lo que sí parece evidente es que los distintos sistemas geniculocorticales activan diferentes grupos de neuronas corticales. Mencionaremos igualmente, que, en carnívoros (gato), el núcleo geniculado lateral, y a diferencia con roedores y primates, no sólo proyecta al área visual primaria V1 o área 17, sino también al área 18, corteza visual secundaria o área V2, que recibe un fuerte contingente de fibras del núcleo geniculado lateral $[80,81,92,93,137,138,294]$. 
El cuadro de terminación de las fibras aferentes corticales en primates difiere considerablemente del observado en otros animales. En el sistema visual, igual que en roedores (rata), pero a diferencia de lo observado en carnívoros (gato), el núcleo geniculado lateral proyecta exclusivamente al área visual primaria, área 17. Esta diferencia aparece obviamente relacionada con el dominio del sentido de la visión, evidenciado morfológicamente por la presencia de uno de los tipos más elaborados de organización cortical, y que ha sido objeto de numerosos estudios para establecer la morfología y distribución de fibras aferentes corticales en general y de la corteza visual en particular. En la corteza visual de primates, la capa IV aparece subdividida en tres estratos claramente diferenciados: subcapas IVa, IVb y IVc, originalmente descritos por Brodmann [23] en preparaciones teñidas por el método de Nissl, siendo sólo el IVa y el IVc los estratos que reciben fibras aferentes procedentes del núcleo geniculado lateral.

En nuestros estudios con el método de Golgi [314] en Macaca y Erithrocebus (Cercopithecidae), las fibras aferentes geniculocorticales ascienden desde la sustancia blanca para ramificarse en los estratos IVa y IVc de la corteza visual primaria (área 17), formando complejos extensos y muy compactos de fibras terminales provistas de numerosas dilataciones en forma de racimos de uvas, que probablemente corresponden a botones sinápticos (Fig. 2c, Faf). Puede observarse en esta figura cómo el estrato IVb, coincidente con la estría de Gennari de la anatomía clásica, queda enteramente libre de estas terminaciones. Otros autores [18,190], empleando el método de Golgi y marcaje anterógrado con HRP, han descrito terminaciones similares en los mismos estratos de la corteza visual, siendo las imágenes así obtenidas enteramente comparables a las observadas con el método de Golgi, y además coincidentes con los niveles de degeneración terminal tras lesiones experimentales en el núcleo geniculado lateral [100,134,309,345].

Existe en primates otro tipo de fibras aferentes a la corteza visual que forman agregados de terminales sinápticos con una apariencia arrosariada en la parte inferior de la subcapa IVc, conocida como IVc $\beta$ [190]. Estos terminales forman conglomerados esféricos, relativamente circunscritos [18] y, según hemos podido comprobar, su tinción con el método de Golgi es bastante más infrecuente [323] (Fig. 10,2). Según numerosas investigaciones, existe en primates una segregación de fibras aferentes más completa que la observada en carnívoros $[65,87,118,133,134]$, segregación probablemente debida a una mayor diferenciación de las fibras procedentes de las células X e Y del núcleo geniculado lateral $[16,17,64,69,123,154,274,278]$.

\section{COMPONENTES NEURONALES DE LA CORTEZA CEREBRAL Células piramidales}

La corteza cerebral de mamíferos posee una inmensa variedad de tipos celulares. No obstante, desde un punto de vista general, y a falta de una mejor clasificación, las neuronas corticales pueden ser agrupadas en dos tipos principales: células piramidales y células no piramidales o intrínsecas, existiendo un consenso general que indica que las células piramidales representan la esencia de la arquitectura cerebral, mientras que la células intrínsecas le añaden el sabor. Las células piramidales representan el tipo fundamental de célula cortical; poseen axones de proyección fuera de la propia corteza, mientras que las células no piramidales o intrínsecas poseen axones que permanecen dentro de la propia sustancia gris de la corteza. Varios estudios han demostrando que las células corticales poseen diferen-

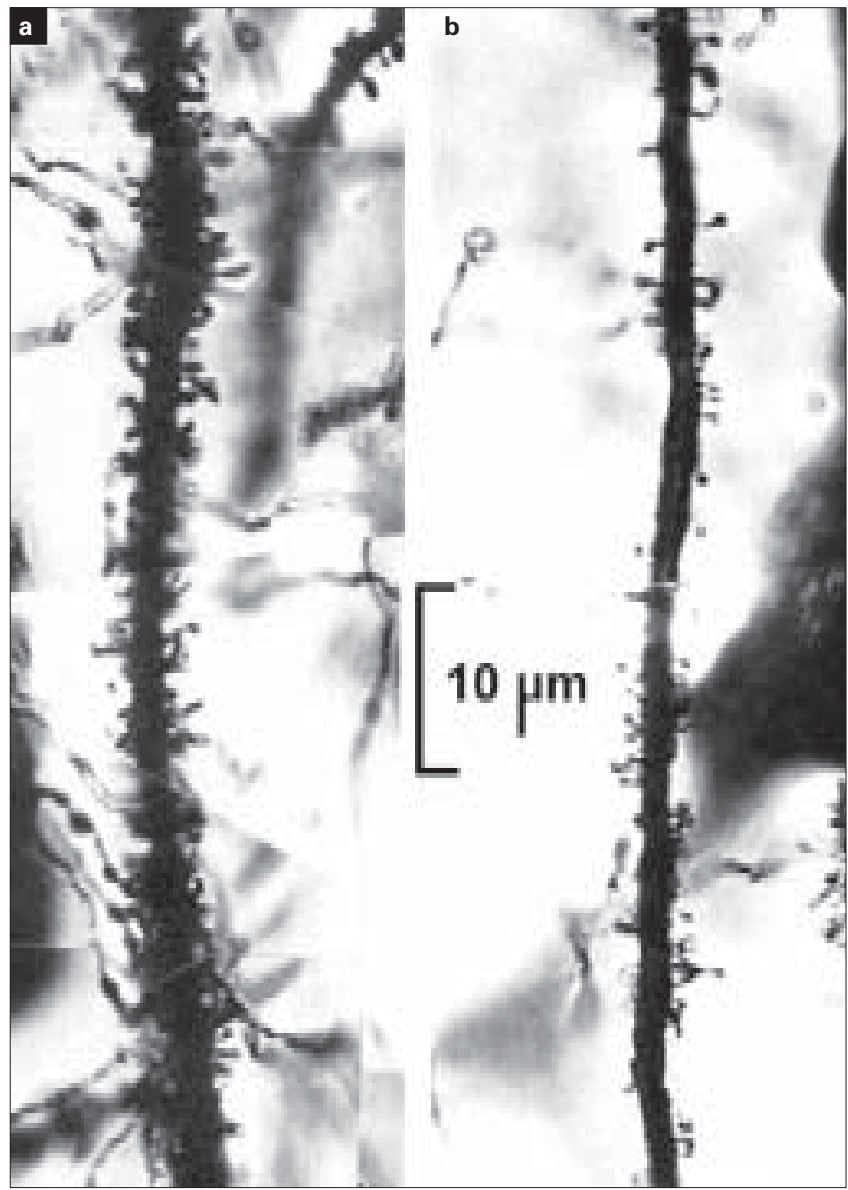

Figura 3. Microfotografías de segmentos de dendritas apicales de células piramidales de la capa $V$ en la corteza visual del ratón (capa IV). a) Ratón normal de 50 días; b) Ratón mantenido en oscuridad total durante 50 días desde su nacimiento. La disminución del número de espinas dendríticas, estadísticamente confirmada [310], es notable en el ratón deprivado (b). Método de Golgi.

tes neurotransmisores empleados como marcadores selectivos para identificar y catalogar distintas poblaciones neuronales [56]. En el caso de las células piramidales, gran número de ellas utilizan los aminoácidos glutamato o aspartato como principal neurotransmisor [39-41,55,295], estando, en algunos casos, sus correspondientes receptores selectivamente localizados [94,139].

Las células piramidales representan aproximadamente el $70 \%$ de toda la población neuronal de la corteza cerebral, y son más abundantes en las capas II-III y V-VI. Su aspecto es claramente diferencial: muestran un tallo apical, o dendrita apical que, en la mayoría de los casos, alcanza la capa I, en donde se ramifica en numerosas colaterales divergentes, y un abanico de dendritas basales originadas en el cuerpo celular que alcanzan distancias variables (ver ejemplos en las figuras 1a, 2c y d, 9b, 10, a-e, n-q). Una característica fundamental, tanto de las dendritas apicales como de las basales de las células piramidales, es que están cubiertas de espinas dendríticas, pequeños procesos colaterales, que aumentan considerablemente la superficie receptora de las dendríticas. La mayoría de las espinas dendríticas están formadas por un pequeño engrosamiento esférico de 1 a $3 \mu \mathrm{m}$ de diámetro, unido por un fino pedículo a la dendrita. La 'cabeza' de la espina dendrítica es la que recibe la inmensa mayoría de las terminaciones axonales formando sinapsis. En mamíferos 'inferiores' las células piramidales predominan de tal forma que tanto las dendri- 
tas apicales como las basales representan las principales dianas para las fibras talamocorticales específicas (Figs. 1a y b; Fig. 2a), y en general, dada la morfología y disposición de sus dendritas apicales, que atraviesan varias capas, puede considerarse que son capaces de analizar y procesar aferencias corticales a cualquier nivel. Disponemos de datos, fundamentalmente de estudios llevados a cabo con el microscopio electrónico, o tras practicar lesiones en núcleos talámicos específicos, que indican que prácticamente todas las sinapsis identificadas como terminaciones talámicas son de tipo asimétrico ${ }^{1}$, es decir, sinapsis excitadoras [238,243,337], por lo que se propuso, un poco alegremente según nuestro punto de vista, que todas las neuronas y dendritas que residen en las capas medias de la corteza, y capaces de formar sinapsis de tipo asimétrico, reciben fibras talámicas [239].

Se ha estimado que un $20 \%$ de terminales axónicos presentes en la capa IV de la corteza visual corresponden a fibras geniculocorticales [49,126,172,337,347] y, más específicamente, en el área visual primaria (área 17), en rata, gato y mono, el 15\% de terminales talámicos identificados, que forman sinapsis asimétricas, hacen contacto sobre la parte lisa de las dendritas; un 3\% contactan sobre los cuerpos celulares, y el restante, aproximadamente un $80 \%$, lo hacen sobre las espinas dendríticas [93,100, $238,247,338,341,342]$. Es cierto que los contactos sinápticos no pueden observarse empleando sólo el método de Golgi, pero utilizando técnicas que combinan este método con microscopía electrónica [75] y lesiones practicadas en diversos núcleos talámicos en la rata y el gato, demuestran convincentemente que la mayoría de las espinas dendríticas que reciben sinapsis talamocorticales pertenecen a dendritas de células piramidales localizadas en las capas III, IV y V, así como, en menor cantidad, a variedades de células intrínsecas situadas en estos estratos [49,93,126, $243,286,337]$. En resumen, la mayoría de los contactos sinápticos excitatorios se realizan sobre espinas dendríticas, mientras que aquellos de naturaleza inhibitoria (sinapsis simétricas) predominan en los cuerpos celulares, dendritas sin espinas y, ocasionalmente, también sobre espinas dendríticas.

De lo que antecede es fácil deducir la importancia que poseen las espinas dendríticas como aparato receptor de la gran mayoría de las neuronas corticales. Las espinas dendríticas son elementos tremendamente plásticos, y ya desde los tiempos de Ramón y Cajal [253] se las consideró como paradigma de estructuras implicadas en procesos de aprendizaje y memoria, existiendo nume-

\footnotetext{
${ }^{I}$ Las sinapsis se han clasificado en simétricas y asimétricas, según la morfología observada con el microscopio electrónico entre terminaciones axónicas y las correspondientes estructuras postsinápticas (dendritas, cuerpos celulares y axones). Ambos tipos están formados por el agrupamiento de vesículas sinápticas, próximo a la membrana presináptica, una hendidura y una membrana postsináptica. Las sinapsis simétricas contienen vesículas ligeramente aplanadas o cilíndricas; la hendidura sináptica es estrecha (20 nm) y la membrana postsináptica, formada de material denso, muy estrecha $(10 \mathrm{~nm})$. Las sinápsis asimétricas muestran vesículas esféricas, la hendidura sináptica es más ancha $(30 \mathrm{~nm})$, y la membrana postsináptica, formada de material electrondenso $(40 \mathrm{~nm})$, fuertemente adherida a la superficie citoplásmica del elemento postsináptico, las distingue con claridad de las anteriores. La diferencia de espesor de ambas membranas pre y postsinápticas en uno y otro tipo justifican su nombre. La asociación fundamentalmente de GABA con las sinapsis de tipo simétrico y de glutamato y aspartato con sinapsis de tipo asimétrico ha sido decisiva para considerar a las primeras como sinapsis inhibidoras, y a las segundas, como excitadoras. Esta clasificación en sinapsis simétricas y asimétricas se debe a Colonnier [34], y las primeras descripciones con el microscopio electrónico las realizaron De Robertis y Bennett [63] y Palade [231], ambas en 1954, lo que realmente representó la mas clara confirmación de la independencia de las células nerviosas: la teoría neuronal formulada por Ramón y Cajal en 1888 [252].
}

rosas teorías sobre su posible función [32,46,66,83,112,251,282, 300,359]. Estudios llevados a cabo por nosotros [310,311,315] demostraron que el número de espinas dendríticas en los tallos apicales de las células piramidales de la corteza visual de ratones mantenidos en oscuridad disminuye con relación al número de espinas que estas dendritas poseen en condiciones normales (Fig. 3) y, lo que nos pareció más interesante, ratones mantenidos en oscuridad total durante períodos prolongados de tiempo, no recuperan el número normal de espinas al retornar a las condiciones normales. De esta forma demostramos que la deficiencia producida por deprivación sensorial es irreversible, hallazgo confirmado por estudios similares llevados a cabo en el gato [344]. Varios autores han sugerido que la formación de espinas dendríticas depende directamente de la actividad receptora de las neuronas [276,279]. Las espinas dendríticas son estructuras móviles -gráficamente se habla de 'la danza de las espinas' [84,114,276], desaparecen tras isquemia experimental y reaparecen al cesar ésta [115]; están implicadas en procesos de memoria [234,256], aprendizaje [101,102], actividad sináptica [276,359] y, por supuesto, su número y morfología están alterados en determinadas patologías [5,220,270] y enfermedades mentales [99,107,157], por citar sólo algunos de los estudios más recientes sobre aspectos, aún no aclarados, del significado y función de estas estructuras.

Los axones de la inmensa mayoría de las células piramidales son fibras de proyección que penetran en la sustancia blanca, no sin antes haber dado origen a cierto número de colaterales que se distribuyen de forma variable dentro de la corteza; en este sentido, existe una gran diversidad con ejemplos de colaterales que se ramifican abundantemente en la vecindad del cuerpo celular, así como colaterales ascendentes, descendentes u horizontales que pueden alcanzar distancias considerables. Las células piramidales que proyectan a otras áreas corticales o a centros subcorticales están localizadas en capas específicas; de esta forma, aquellas que proyectan a otras zonas del mismo hemisferio cerebral, o a través del cuerpo calloso, habitan preferentemente en las capas II y III [227,338,340], mientras que aquellas que proyectan a centros subcorticales, fundamentalmente corticotalámicas, residen en las capas V y VI, como han demostrado numerosos estudios llevados a cabo con distintos trazadores y técnicas y para diferentes áreas corticales, en el ratón y rata [143,340], gato [104] y mono $[152,194,195]$. Existen numerosos estudios, que sería prolijo detallar aquí, sobre las conexiones que efectúan las colaterales y ramas terminales de los axones de las células piramidales sobre variedades de células intrínsecas y sobre dendritas de otras células piramidales dentro de la propia corteza, estudios que han sido ampliamente revisados [56,338], pero lo que sí nos parece interesante resaltar es la existencia de una distribución especial mediante la cual, no sólo las ramificaciones axonales de células piramidales, sino las propias células piramidales que las originan, aparecen agrupadas en estrechas zonas radiales que ocupan todo el espesor de la corteza, y que claramente definen una serie de módulos o columnas de unas 500 $\mu \mathrm{m}$ de diámetro, dándose la notable circunstancia de que el tamaño de estas columnas permanece constante cuando se comparan especies con distinto tamaño cerebral $[26,109,277]$. Este hecho suministra datos adicionales sobre la organización columnar de la corteza cerebral, esbozado en nuestra Introducción, y que detallaremos más adelante (ver Organización modular de la corteza cerebral).

\section{Células intrínsecas}

Las células intrínsecas (células de axón corto, células de tipo II de Golgi, según la terminología clásica), cuyo axón se resuelve dentro de la propia corteza, se han clasificado de varias formas. Una pri- 
mera aproximación viene dada por el hecho de que una parte de ellas tiene dendritas lisas, sin espinas, mientras que otro grupo posee dendritas cubiertas de espinas. A estas últimas se las denominó 'células estrelladas con espinas', si bien pronto se comprobó que no forman una población uniforme, ya que existen notables diferencias entre ellas. En un intento de perfilar un poco más la clasificación de células intrínsecas de la corteza cerebral, se recurrió a un criterio basado en la densidad de las espinas dendríticas, de tal forma que podríamos mencionar células con dendritas lisas, células con dendritas con pocas espinas y células con dendritas cubiertas de espinas en número y distribución similar a las dendritas de las células piramidales [237]. Evidentemente, y desde un punto de vista morfológico, ninguno de estos criterios ha sido útil, por lo que debemos considerar otros aspectos, como son la forma y distribución del árbol dendrítico, el tamaño celular y, principalmente, la forma y distribución del ramaje axonal. Es, además, de sobra conocido que las células intrínsecas poseen una gran variedad de neurotransmisores que pueden ser empleados como marcadores específicos para catalogar distintas poblaciones neuronales, y que reflejan aspectos diferentes de conectividad cortical $[56,73,96,166]$.

Durante el desarrollo embrionario, las células piramidales y algunas células intrínsecas de la corteza cerebral poseen orígenes diferentes. Las primeras se originan en la zona ventricular de la vesícula telencefálica ascendiendo hacia la superficie guiadas por los procesos de la glía radial [110,211,248,249,328]. Por el contrario, poseemos evidencia muy reciente de que tanto la zona ventricular como subventricular de unas estructuras transitorias del telencéfalo basal -las eminencias ganglionares, futuros ganglios basales-son el lugar de origen de otra población de células neocorticales. Estudios llevados a cabo en nuestro laboratorio demostraron por primera vez que estas células, procedentes de las eminencias ganglionares, emigran tangencialmente cruzando el límite corticoestriatal para penetrar en el neuroepitelio cortical [52]. Posteriormente se ha demostrado que estas células son GABAérgicas, no son transitorias y se diluyen en el espesor de la corteza cerebral durante el desarrollo, contribuyendo, en una proporción considerable, a la población de células intrínsecas de la corteza $[6,8,233,306,361]^{2}$.

En el estudio y clasificación de las células intrínsecas, el método de Golgi [313,324] ha permanecido como el proceder de elección. El hecho de que este método, y varias de sus modificaciones, impregnen selectivamente un pequeño número de células, pero casi siempre la totalidad del árbol dendrítico y axonal, lo ha convertido en el proceder de elección para estudiar, de forma individual, distintos tipos neuronales, pudiendo asegurarse que la gran mayoría de las células intrínsecas, sus diferencias entre distintas especies y sus variaciones con relación a las áreas corticales en donde habitan, han sido descritas empleando esta técnica. Basándonos en estudios realizados con este método, propusimos una clasificación [76], que, con ligeras variaciones, exponemos a continuación, resaltando sus características más sobresalientes. Prescindimos de referirnos a las células de Cajal-Retzius de la capa I por entender que su descripción y significado, relacionado con el desarrollo embrionario, no corres-

\footnotetext{
${ }^{2}$ Siendo de sobra conocido el hecho de que no hay generación de neuronas fuera de la etapa embrionaria en los mamíferos (con la excepción del hipocampo y del bulbo olfativo), causó verdadera sorpresa un reciente estudio que sugería que la zona subventricular del ventrículo lateral en el macaco adulto es el origen de una población adicional de neuronas, las cuales emigran, siguiendo las fibras de la sustancia blanca, para incorporarse a varias zonas del neocórtex. Estas neuronas emiten axones cortos y pueden entrar a formar parte de circuitos intracorticales [110]. De ser ciertas, estas observaciones tendrían profundas implicaciones para entender algunos mecanismos relacionados con la memoria y otras funciones superiores del cerebro. Otros autores han cuestionado seriamente [225], o han negado con rotundidad [165], la existencia de tal generación neuronal en el neocórtex adulto. Por su interés, el hecho de que células con propiedades similares a las células madre pudieran dar origen a una población neuronal funcionalmente activa, se ha revisado recientemente en Journal of Neuroscience, volúmen 22, de 1 de febrero de 2002, en donde varios autores exponen distintos puntos de vista y contrastadas experiencias.
} 


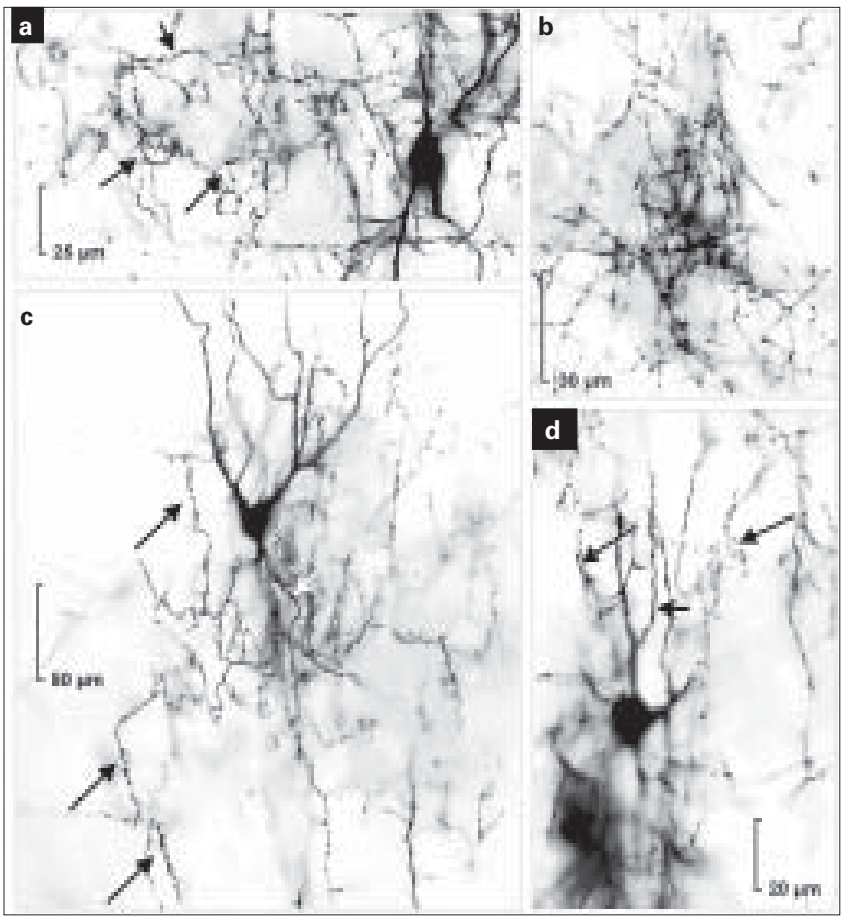

Figura 5. a) Microfotografía de una célula cuyo axon (señalado por una flecha de brazo corto) forma cestos pericelulares (flechas) en el stratum pyramidale del hipocampo de la rata de 1 mes. El origen del axon en la célula a la derecha está fuera de foco. Método de Golgi; b) Cesto o nido pericelular en torno a una célula piramidal de la capa $V$ en la corteza motora de un niño recién nacido. Método de Golgi. Microfotografía de una preparación efectuada por Ramón y Cajal; c) Microfotografía de una célula en candelabro de la corteza visual del gato de un mes. El orígen del axon está señalado por una flecha de brazo corto; las flechas de brazo largo señalan la disposición de botones sinápticos en hileras verticales formando los 'candiles' típicos de esta variedad celular. Método de Golgi; d) Microfotografía de una célula en candelabro de la corteza visual del mono adulto (Erithrocebus). La flecha de brazo corto señala el origen del axon en una dendrita proximal; las flechas de brazo largo indican las hileras verticales formando 'candiles'. Método de Golgi. Tanto en 'c' como en 'd', los segmentos iniciales de los axones de células piramidales que reciben los contactos suinápticos no aparecen teñidos.

ponde a la estructura del neocórtex en el adulto. Los encabezados de esta clasificación nos parecen lo suficientemente didácticos como para expresar de una forma intuitiva su morfología más característica.

\section{Células con axones ramificados} en la proximidad del cuerpo celular

Este grupo está compuesto por variedades celulares de distinto tamaño, multipolares y con dendritas lisas, cuyo axón se ramifica en las vecindades del cuerpo celular, generalmente en el mismo estrato, o en niveles siempre superiores al cuerpo celular, pudiendo llegar a alcanzar la capa I (Fig. 2a; Fig. 4, 1-7). Se trata de un grupo de células sin aparente uniformidad, que aparecen caracterizadas, en parte, como células de tipo II de Golgi, o células de axón corto en los estudios clásicos [185,187,229,254]. Están situadas en todas las capas corticales y puede suponerse que, dependiendo de su localización, los impulsos aferentes que reciban habrán de ser distintos. Se han descrito variedades celulares de este tipo, utilizando el método de Golgi, prácticamente en todas las especies y áreas corticales estudiadas y, específicamente, en la corteza visual del ratón [76,269,316], rata [79], conejo [229], mono [148] y hombre [254], y somatosensorial del ratón [185], siempre con las variaciones morfológicas que corroboran su falta de uniformidad.

\section{Células de axón ascendente}

Están representadas por variedades de células multipolares que poseen dendritas lisas o cubiertas con un número escaso de ellas. Existen en todos los animales estudiados y constituyen una variedad relativamente común. El axón se origina normalmente del polo superior del cuerpo celular y asciende directamente ramificándose al alcanzar la capa I (Fig. 2, d y g; Fig. 4, 8-15). Durante el curso ascendente, el axón emite colaterales distribuidas en varias capas corticales, siendo éstas, en muchos casos, relativamente escasas al predominar su ramificación en la capa I. Este tipo de células se ha localizado en todas las capas corticales, excepto en la capa I, haciendo notar que la rama principal del axón de aquellas situadas en las capas altas II y III posee largas trayectorias horizontales en la capa I, mientras que las situadas más profundamente en las capas IV a VI apenas contribuyen a la capa I, pero lo que realmente las distingue del grupo anterior es el grosor del tronco principal del axón y su 'decidida' trayectoria ascendente o mixta (ascendente y horizontal, según su posición). Las situadas más profundamente corresponden al tipo de células de Martinotti descrito por Ramón y Cajal [254]. Células de axón ascendente, aparte de en los estudios clásicos [185,187,229,254], se han descrito, en épocas recientes, en la corteza visual del ratón [76,269,316], gato [228] y mono [190].

\section{Células con arcadas axonales recurrentes}

Estas células poseen dendritas lisas o presentan un número muy reducido de espinas dendríticas. Las hemos descrito en todas las capas corticales del área visual del ratón, excepto en la capa I [312,316]. El axón emerge del polo superior del cuerpo celular, asciende verticalmente y puede emitir algunas colaterales ascendentes y horizontales, pero lo más característico corresponde al desarrollo de toda una serie de ramas recurrentes, descendentes y oblicuas, que pueden alcanzar distancias considerables que recuerdan vagamente la imagen del ramaje de los sauces (Fig. 4, 16-18). A este tipo celular corresponden variedades descritas en las cortezas visual [190] y somatosensorial del mono [148].

\section{Células con axón formando cestos pericelulares} (células en cesto)

Esta variedad celular está representada por células multipolares, con dendritas lisas y axón desarrollado en largas colaterales horizontales, cuyas ramificaciones terminales forman nidos o cestos pericelulares en torno a los cuerpos, en la mayoría de los casos, de células piramidales (Figs. 5a y b). Fueron descritas por primera vez por Ramón y Cajal [254] en las cortezas visual y motora del hombre (Fig. 5b), y más recientemente se han descrito variedades en diversas áreas de la corteza cerebral del gato [301], mono [148] y hombre [198,199]. Esta variedad celular ha sido materia de considerable debate, y su existencia, en otras especies distintas a primates y carnívoros, se mantiene a falta de una clara evidencia $[74,150]$. Lo que sí es notorio es que, con el método de Golgi, no es raro encontrar grupos de finas ramas terminales provistos de múltiples botones formando densos nidos pericelulares, que alojan en su interior cuerpos celulares no teñidos. Algunas de estas ramas terminales pueden ser trazadas hasta otras ramas axonales de mayor calibre y curso horizontal, suponiendo que, en algunas de estas células de tamaño grande, el axón está mielinizado y no se ha teñido con el método de Golgi [148,242], por lo que es imposible seguir su trayecto completo. Tampoco hemos de olvidar que existe una cierta convergencia de terminaciones axonales de otras células [90,237,242], por lo que cabe suponer que varios 


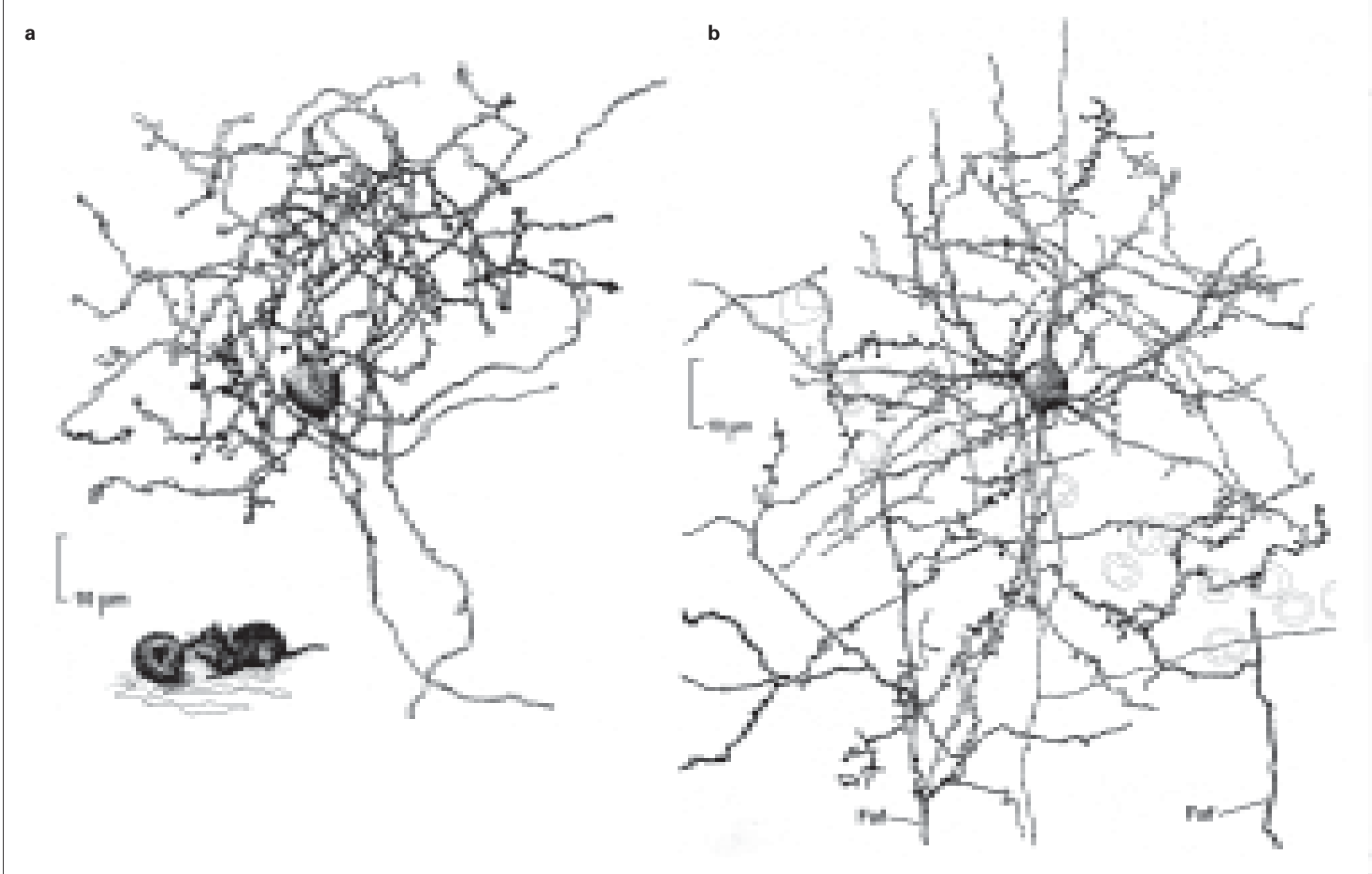

Figura 6. a) Célula en ovillo típica de la capa IVc de la corteza visual del mono adulto (Macaca mulatta) que muestra dendritas cortas y arrosariadas y un axon que forma un apretado ovillo en torno al cuerpo celular. El origen del axon está señalado por una cabeza de flecha. Método de Golgi; b) Célula estrellada con espinas de la capa IVc de la corteza visual del mono adulto (Macaca mulatta). El origen del axon está señalado por una flecha. La imagen muestra ramificaciones terminales de fibras aferentes específicas (Faf) con algunas colaterales terminales realizando (presumibles) contactos sobre las dendritas de esta célula. Método de Golgi. Dibujos a la cámara clara. Tomadas de [319] y reproducidas con autorización de Plenum Press.

tipos neuronales están implicados en la edificación de estos cestos pericelulares. Células con axones formando nidos pericelulares, como células en cesto, se han descrito en el hipocampo (Fig. 5a) y fascia dentata $[186,254,259]$.

Estudios llevados a cabo con inmunorreactividad para GABA demostraron la convergencia de múltiples terminaciones axonales GAD-positivas en torno a cuerpos de células piramidales [258], formando sinapsis de tipo simétrico [34,124,151,240]. Se considera que muchas de estas terminaciones provienen de células en cesto y que por lo tanto, dada su ubicación en torno a los cuerpos celulares y ramas dendríticas proximales, son capaces de ejercer una poderosa acción inhibidora sobre ellas [119,161,292]. Estas características sugieren que las células en cesto gabérgicas pueden ser activadas monosinápticamente por fibras aferentes extrínsecas y transmitir una fuerte acción inhibidora sobre poblaciones de células piramidales. De esta forma, la activación de células en la corteza, que integran una agrupación columnar con similares campos receptivos, produce una inhibición de las columnas vecinas [218]. Sin embargo, el aspecto más interesante de estas células quizás corresponda a los estudios llevados a cabo en pacientes epilépticos (se han descrito alteraciones significativas en el número de sinapsis simétricas -inhibidoras- en focos epilépticos [60,196,197], y las implicaciones de las células en cesto del hipocampo y fascia detata [259] en modelos experimentales de epilepsia (p. ej., hipótesis de 'la célula en cesto durmiente' [13,14]), detalles que no trataremos aquí por considerarlos fuera del contexto de esta revisión.

\section{Células en candelabro}

Estas células reciben este curioso nombre debido a la morfología de sus axones, cuyas ramas terminales forman series de botones sinápticos dispuestos en hileras verticales ('candiles'), recordando el aspecto de una lámpara de brazos (Fig. 2b, a; Figs. 5c y d). Fueron descritas por primera vez en el gyrus cinguli del gato [305], y se sugirió que los agregados verticales de botones terminales establecían contacto con los tallos apicales de células piramidales [302]. Sin embargo, estudios posteriores llevados a cabo con la técnica de Golgi y microscopía electrónica [75] demostraron que estos agregados de botones establecen contactos de tipo simétrico, con los segmentos iniciales de los axones de las células piramidales, por lo que han sido también denominadas 'células axo-axónicas' [285]. Utilizando la misma técnica, nosotros confirmamos la presencia de estas células en la corteza visual del gato [77] y desde entonces numerosos estudios han demostrado que las células en candelabro no son privativas de la corteza visual, como se pensó al principio, sino que han sido descritas en diferentes áreas, tanto en la neocorteza como en el hipocampo y corteza olfativa, y en todos los animales estudiados, desde insectívoros a primates [50,51,54,74, $77,162,200,235,289,293,318]$. Las células en candelabro son probablemente, y al igual que las células en cesto, GABAérgicas [58,91,244,290], y se ha comprobado que las hileras terminales de sus botones sinápticos muestran inmunorreactividad para parvoalbúmina (proteína ligadora del calcio encontrada abundantemente en subpoblaciones de células GABAérgicas) [57,117,179]. 


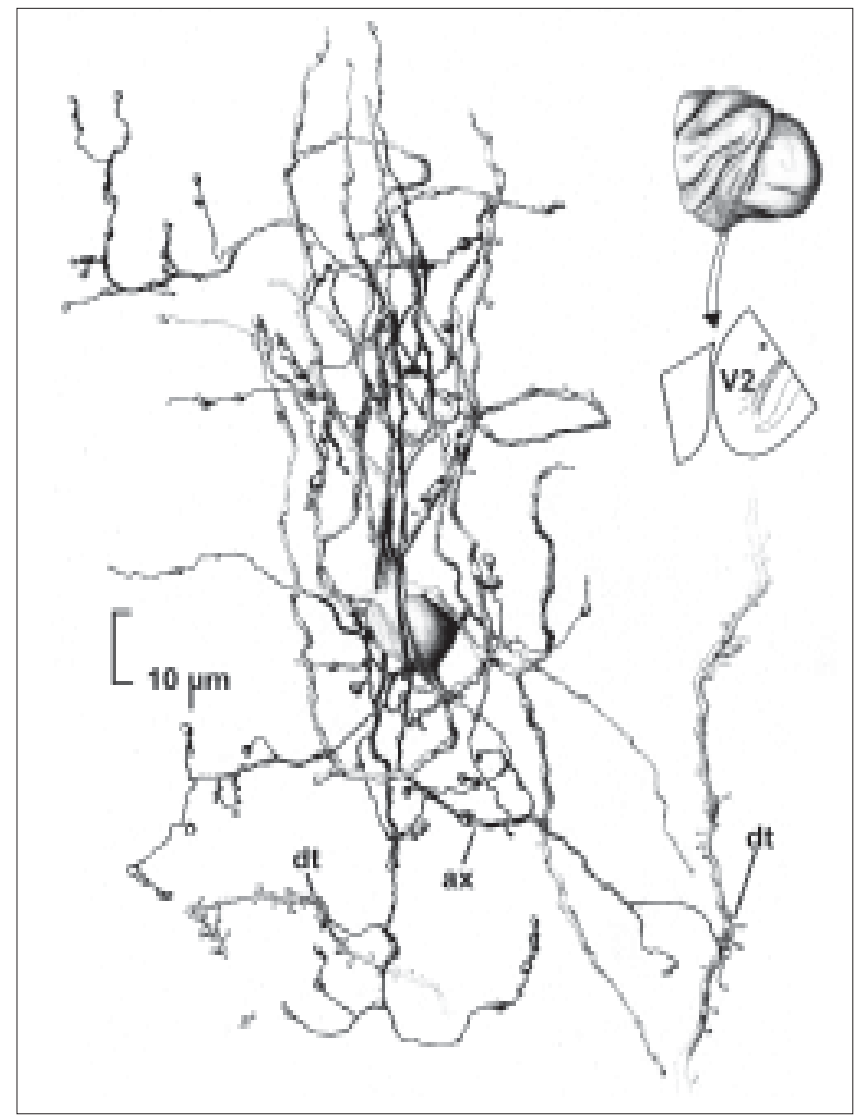

Figura 7. Célula en ovillo de la capa IV en la corteza visual secundaria, área 18, del mono adulto (Macaca rhesus). El axon (ax) forma un conjunto de ramificaciones de distribución local y provistas de botones terminales en estrecha relación con segmentos de dendritas de células vecinas (dt) que parecen indicar contactos sinápticos. Método de Golgi. Dibujo a la cámara clara. Tomada de [317] y reproducida con autorización de Springer.

Las células en candelabro representan, hasta ahora, un único ejemplo de especificidad sináptica. Dada la naturaleza y la disposición de los terminales axónicos ('candiles') de estas células en torno a los segmentos iniciales del axón de las células piramidales, era lógico suponer su poderosa acción inhibidora sobre éstos, por lo que se ha sugerido que la pérdida o disminución de los terminales axónicos de células en candelabro podría representar un factor precipitante de la epilepsia [53]. En cualquier caso, se ha considerado que la alteración de circuitos corticales en los que intervienen estas células podría, igualmente, estar relacionado con la esquizofrenia [178] y la enfermedad de Alzheimer [89].

\section{Células en ovillo}

También conocidas como 'neurogliaformes' o 'en tela de araña', las identificamos por primera vez en la capa IV de la corteza visual del gato [76] y mono [314] como una variedad celular de cuerpo pequeño, dendritas lisas y arrosariadas y un axón que rápidamente se resuelve en un apretado ovillo de colaterales formando un plexo denso en torno al cuerpo celular (Fig. 2B, e; Fig. 2C, g; Fig. 6a; Fig. 10, m). Se han descrito células similares en la corteza visual del gato $[164,195]$ y somatosensorial del mono [148], y nosotros describimos una variedad comparable en el área 18, área visual secundaria, en el mono [317] (Fig. 7). Estudios posteriores han demostrado que las células en ovillo conectan preferentemente con

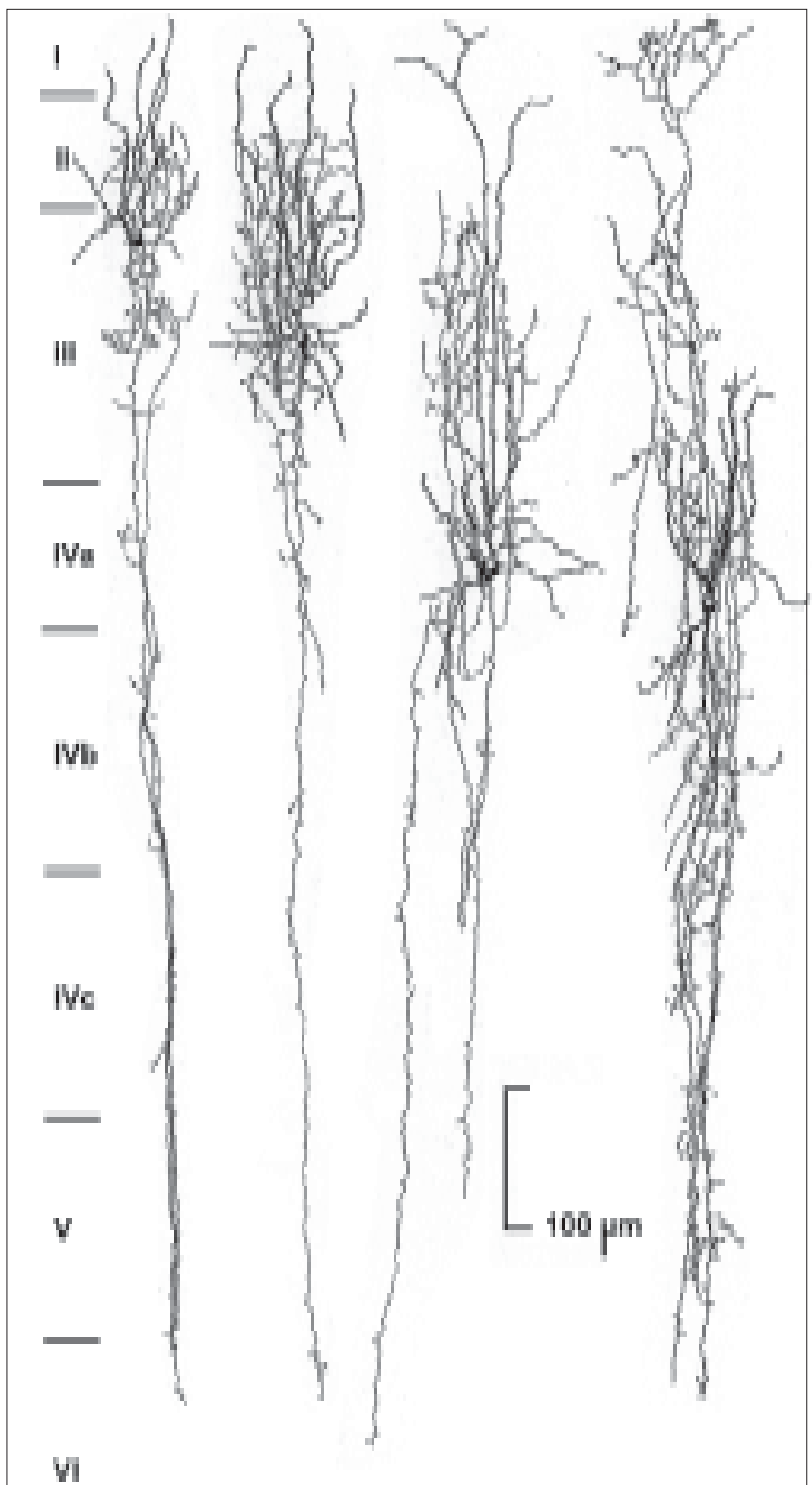

Figura 8. Variedades de células con axones formando fascículos verticales. Células bipenachadas o double bouquet cells en la corteza visual del mono adulto (Macaca mulatta). Si bien la posición del cuerpo celular varía, los axones se extienden cubriendo prácticamente todas las capas corticales. Método de Golgi. Dibujo a la cámara clara. Modificada de [319] y reproducida con autorización de Plenum Press.

determinadas células estrelladas con espinas, y la presencia de GABA en ellas ha sugerido su papel inhibidor sobre las células estrelladas [162]. Es posible que esta variedad celular corresponda a algunos elementos descritos por Ramón y Cajal [254] en las cortezas visuales de gato y hombre como 'células aracneiformes', si bien la morfología nos ha parecido ligeramente distinta.

\section{Células bipenachadas}

En la edición francesa de Histologie du systèmenerveux de l'homme et des vertébrés, Ramón y Cajal [254] se refirió a esta variedad celular como 'cellule à double bouquet dendritique', conociéndolas en la literatura anglosajona como 'double bouquet cells', nombres sobradamente descriptivos como para expresar su peculiar morfología. Estas neuronas, con ligeras variaciones, presentan un 
doble penacho dendrítico, ascendente y descendente, orientado radialmente (perpendicular a la piamadre) y una arborización axonal que se resuelve en haces compactos de fibras, ascendentes, descendentes o ambos, y dispuestas igualmente de forma radial, pudiendo atravesar varias capas corticales, desde la capa II hasta la V (Fig. 8). Nosotros describimos estas células en las capas II y III del área 18 del mono [317], y posteriormente fueron descritas en varias áreas corticales en la rata, gato y mono [237,287,288].

Se ha demostrado que las células bipenachadas son GABAérgicas, formando sinapsis simétricas, inhibidoras, sobre las dendritas basales y colaterales de los tallos apicales de células piramidales [59,61,287]; debido a la peculiar disposición de sus axones, radialmente orientados, se pensó que formarían agregados 'microcolumnares' como componentes integrantes de la organización columnar de la corteza [61,62,288].

\section{Células bipolares}

A menudo confundidas con las células bipenachadas, corresponden a elementos de tamaño pequeño, cuyo cuerpo no sobrepasa las 10-12 $\mu \mathrm{m}$ de diámetro, de forma ovalada y con dos grupos de dendritas radialmente opuestos y extendidos en sentido perpendicular a la superficie pial, siendo muy común la presencia de una sola dendrita emanada de cada polo del cuerpo celular. Con el método de Golgi se ha descrito su presencia en las capas superficiales de las cortezas visual y cingulada de la rata [79,241,331] y visual del gato [245]. El axón se origina generalmente del cuerpo celular o de una dendrita proximal, formando un escaso número de colaterales extendidas radialmente, habiéndose comprobado que, algunas de ellas, forman sinapsis excitadoras (lo que a pesar de su parecido, las diferencia de las células bipenachadas) sobre dendritas y espinas dendríticas de células piramidales superficiales y profundas [236]. Se ha demostrado de forma conclusiva que fibras talamocorticales $[241,336]$ y colaterales recurrentes de células piramidales profundas [206] establecen contactos excitadores sobre estas células.

\section{Células estrelladas con espinas}

Esta variedad celular no constituye un grupo uniforme, pues no sólo conocemos diferencias en su morfología dendrítica y axonal, sino que también las relaciones sinápticas que establecen aparecen diferentes. Sin embargo, poseen una característica común que las diferencia de todos los grupos anteriormente descritos, y es la de tener sus dendritas cubiertas de espinas, en muchos casos de forma similar a las dendritas de las células piramidales. Los axones de estas células forman sinapsis asimétricas, excitadoras [169], característica adicional que también las asemeja a las células piramidales. Dada su importancia como elementos receptores de las fibras aferentes talámicas, varios estudios han demostrado que su proporción varía dependiendo del animal y del área cortical. Refiriéndonos a la capa IV, en la corteza somatosensorial del ratón, aproximadamente el $50 \%$ son células estrelladas con espinas [357]; en la corteza visual de la rata, su proporción es del 10\% [79]; en la corteza visual del gato, su proporción varía entre el 30 y el $40 \%$ [97,346], mientras que en la corteza visual del mono pueden llegar a constituir el 95\%, siendo el resto células con dendritas lisas de cualquiera de las variedades descritas anteriormente [204]. No se han descrito células estrelladas con espinas en la corteza visual del ratón, pero sí, y ocasionalmente, en las capas III y IV de la corteza auditiva del conejo [207]. En estudios realizados en el erizo (insectívoros) no nos fue posible encontrar nada parecido a esta variedad celular [318].
En la corteza somatosensorial correspondiente al 'campo de barriles' en roedores, las células estrelladas con espinas son particularmente abundantes [357], correspondiendo probablemente a las células estrelladas o granos de Lorente de Nó [185]. Sus dendritas están cubiertas de numerosas espinas, y la orientación dendrítica depende de que el cuerpo celular se encuentre en la pared del 'barril', con dendritas dirigidas hacia el centro del mismo, o que se localice en su centro, en cuyo caso presentan una disposición extendida en todas direcciones. En el gato, nosotros describimos estas células con el método de Golgi, en la capa IV de la corteza visual [76], en donde muestran cuerpos celulares relativamente grandes (15-20 $\mu \mathrm{m}$ de diámetro) y dendritas extendidas en todas direcciones y adornadas con numerosas espinas dendríticas. El axón se origina generalmente del polo inferior del cuerpo celular y se ramifica prontamente en numerosas colaterales de curso horizontal o ascendente (Fig. 2b, b-d). Algunas de estas colaterales alcanzan grandes distancias, circulando en la misma capa IV, o ascendiendo muy oblicuamente a estratos más superficiales. En varias observaciones pudimos trazar la rama principal del axón descendiendo hasta la sustancia blanca, y también nos fue posible observar alguna rama terminal en íntimo contacto con espinas de las dendritas apicales de células piramidales de forma que sugerían contactos funcionales.

Las células estrelladas con espinas fueron motivo de considerable interés desde que se demostró que neuronas situadas en la capa IV de la corteza visual del gato, con campos receptivos simples (posibles receptoras de conexiones talamocorticales directas), identificadas posteriormente mediante inyecciones por iontoforesis de un colorante, eran efectivamente variedades de células estrelladas con espinas [159]. Las neuronas caracterizadas de esta forma son en todo similares a las descritas en estudios llevados a cabo con el método de Golgi [76,169,195,209,228,245,254,255], quedando claramente demostrado que reciben contacto directo de terminales aferentes talámicos [93,126,203] y que, algunas de ellas, especialmente aquellas localizadas en el borde $17 / 18$, poseen axones que conectan con el hemisferio contralateral [125,141,208,271]. El hecho de que algunas de estas células proyecten a la sustancia blanca había sido mencionado por Ramón y Cajal [255] y confirmado posteriormente mediante inyecciones intracelulares de marcadores específicos [105,181].

En primates, las células estrelladas con espinas ofrecen una morfología marcadamente diferente. En los monos que nosotros hemos estudiado (Macaca y Erithrocebus), y en general en todos los primates, la capa IV en el área visual primaria (área 17), se encuentra dividida en tres estratos denominados IVa, IVb y IVc; en esta última se encuentra una población de células estrelladas con espinas que poseen un axón recurrente y cuya morfología es enteramente diferente a sus homónimas descritas en el gato. El cuerpo celular es de menor tamaño (10-12 $\mu \mathrm{m})$, sus dendritas aparecen igualmente cubiertas de espinas y es frecuente la presencia de una dendrita apical que asciende verticalmente durante un corto trayecto para acabar sin ramificarse en capas superiores, sin alcanzar la capa I. Pero lo que fundamentalmente las caracteriza es el axón que, a escasa distancia de su origen en el polo inferior del cuerpo, forma un asa cerrada que recuerda la curvatura de un anzuelo, tornándose en una o varias fibras ascendentes que alcanzan la subcapa IVa y la parte baja de la capa III, en donde acaban ramificándose en colaterales horizontales (Fig. 2c, h-j; Fig. 6b; Fig. 9, c y d; Fig. 10, i-k). Nosotros describimos estas células [314] como elementos especiales de la corteza visual en primates, habiendo sido de un gran interés en el análisis de la organización anatómica y funcional de la corteza visual, en donde, a pesar de diversas 


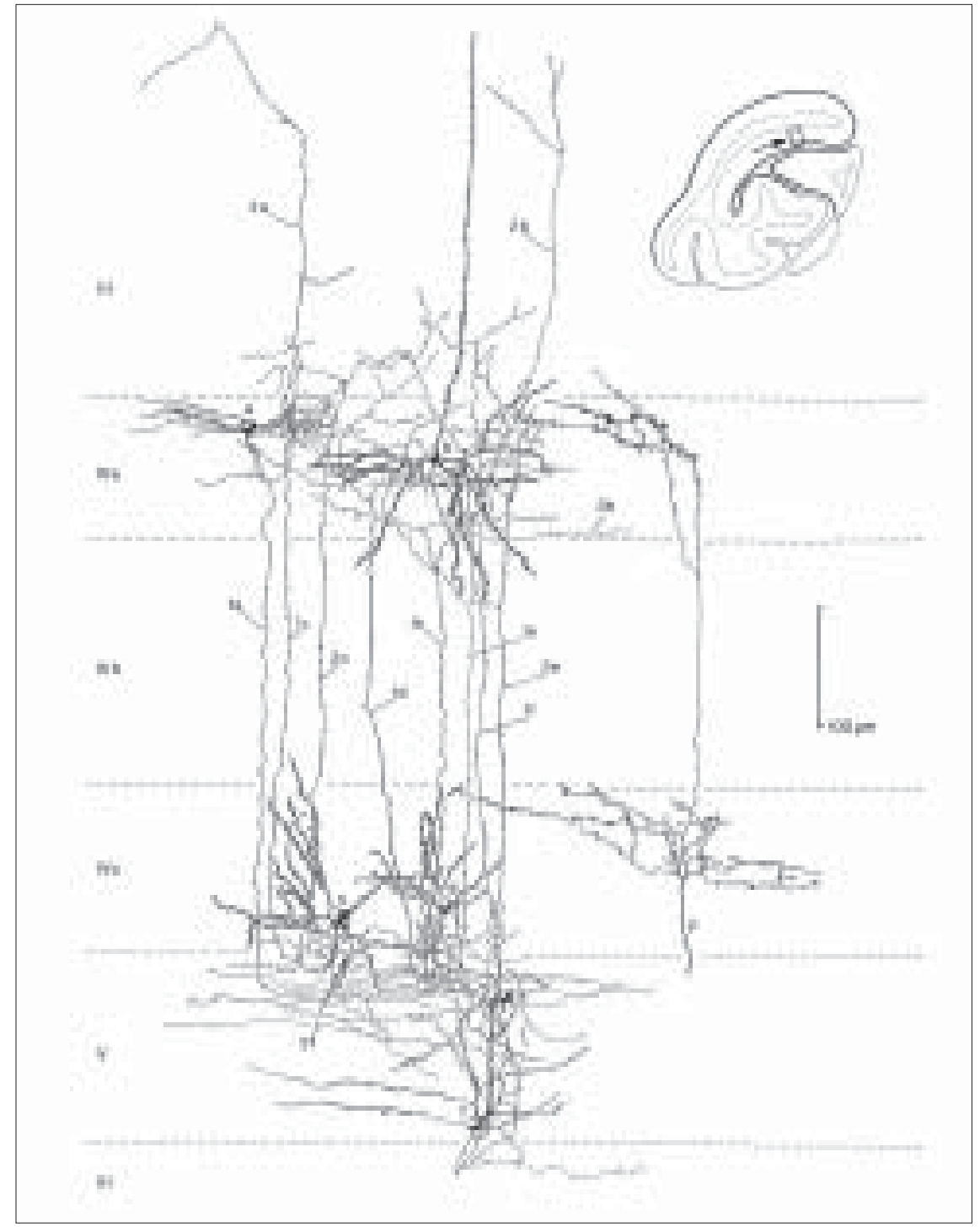

Figura 9. Relaciones interlaminares entre variedades celulares en las capas medias de la corteza visual del mono adulto (Macaca mulatta). La célula a en la capa IVa posee un axon descendente (1a) y una colateral retrógrada (2a) alcanzando niveles superiores; la célula b es una célula piramidal con axon descendente (1b) ramificado en la capa $\mathrm{V}$, y colateral ascendente (2b) y horizontal (3b); las células c y d, en la capa IVc, y las e y f corresponden a células estrelladas con espinas y característicos axones recurrentes que ascienden hasta la capa IVa y parte baja de la III. A la derecha aparece una fibra aferente (F) ramificándose exclusivamente en los estratos IVa y IVc. El esquema de la esquina superior derecha indica la zona de donde se han extraído el conjunto de células. Método de Golgi. Dibujo a la cámara clara. Tomada de [319] y reproducida con autorización de Plenum Press.

talámicas; además, su presencia, con similares características morfológicas se ha demostrado en las cortezas somatosensorial [148] y visual secundaria (área 18) [317].

\section{CIRCUITOS INTRÍNSECOS DE LA CORTEZA CEREBRAL}

Una vez conocidas las principales vías de entrada y los componentes de la corteza cerebral, es lógico saber cómo están conectados entre sí, o dicho en otras palabras, cómo se organiza el 'cableado' de sus distintos elementos dentro de la propia corteza cerebral. Todavía no se han descubierto muchos circuitos intracorticales debido a la dificultad que entraña la identificación de los elementos pre y postsinápticos en una misma preparación, entendiendo con ello la caracterización de las variedades neuronales que intervienen en una determinada articulación sináptica. El modelo básico de conectividad intracortical comúnmente aceptado, que puede extenderse a todas las áreas de recepción primaria (somatosensorial, auditiva y visual), estábasado en estudios llevados a cabo en la corteza visual primaria del gato [103,201], y que, en resumen, es el siguiente: la entrada principal (fibras aferentes de los núcleos talámicos específicos) se realiza sobre la capa IV; las neuronas de esta capa proyectan fundamentalmente a las capas II y III; estas últimas lo hacen sobre la capa V, la que a su vez, lo hace sobre la capa VI y, finalmente, las capas V y VI proyectan a las capas II y III y a la IV, respectivamente (Fig. 10). Dentro de este esquema, en cierto modo bastante grosero, existe una organización mucho más compleja que relaciona entre sí variedades neuronales, y partes de ellas, en muchos casos de forma única.

Gran parte de nuestros conocimientos sobre los circuitos intrínsecos de la corteza se han obtenido empleando el método de Golgi con microscopía electrónica [75], mediante el cual distintas variedades neurona-

consideraciones, siempre las contemplamos como una variedad específica que probablemente no tenga equivalente en otras especies. Se han descrito numerosas variedades de acuerdo con su posición en la subcapa IVc (que adicionalmente se ha subdividido en los estratos IV c $\alpha$ y IVc $\beta$ ), variaciones en la longitud y orientación de sus dendritas y alcance y ramificación de sus axones ascendentes [190-193,195]. Existen, además, variaciones con respecto a la posición de estas células en las distintas subdivisiones de la capa IV, de tal forma que pueden alcanzarse considerables niveles de complejidad, no sólo con respecto a la terminación de fibras aferentes talamocorticales, sino también con relación a las conexiones intrínsecas que estas células reciben [192,195]. Las células estrelladas con espinas en la corteza visual de los primates ocupan la zona principal de terminación de las fibras aferentes talamocorticales, por lo que es lógico deducir que ellas son los principales receptores de las fibras les, identificadas con el método de Golgi, son posteriormente analizadas en el microscopio electrónico con objeto de determinar el tipo neuronal sobre el cual realizan la conexión. Otras técnicas, como inyecciones intracelulares, transporte retrógrado de peroxidasa de rábano (HRP) o reconstrucciones seriadas de procesos identificados con microscopía electrónica, también resultaron apropiados para el establecimiento de conexiones intracorticales, señalando que la situación ideal es aquella en la que ambos elementos aparecen teñidos o marcados en la misma preparación [291].

Muchas de las conexiones intrínsecas de la corteza ya han sido esbozadas al tratar aspectos de la morfología de sus distintas variedades celulares. Los primeros diagramas de conectividad intracortical fueron expuestos de forma magistral por el propio Ramón y Cajal [254] y su discípulo Lorente de Nó [187], quienes, basándose exclusivamente en el método de Golgi, fueron capaces de presumir 
gran variedad de relaciones interneuronales confirmadas en estudios posteriores. De esta forma, es conocidoel hecho de que los plexos dendríticos se distribuyen en distintas capas corticales de forma característica para cada variedad celular y que, conociendo la zona o capa de terminación de un determinado sistema de fibras, es válido deducir su relación funcional; por ejemplo, las dendritas apicales de las células piramidales aumentan la superficie receptora al atravesar distintas capas, como ocurre selectivamente con su penacho dendrítico terminal en la capa I [187,192,193]. La distribución de espinas dendríticas a lo largo de los tallos apicales de las células piramidales también muestra notables variaciones en su número y distribución, aumentando o disminuyendo, al atravesar distintas capas corticales, por lo que es lógico deducir variaciones en el número de contactos sinápticos que reciben y de donde los reciben, por ejemplo, al atravesar la capa IV o zona de terminación de las fibras aferentes talamocorticales [310,330]. Conocemos la existencia de células piramidales, sobre todo aquellas situadas en las capas profundas de la corteza, cuyos tallos apicales no alcanzan la capa I, formando su penacho terminal en la capa III o incluso en capas inferiores, por lo que no habrán de recibir influencias de las capas más superficiales (Fig. 10, n, o y q).

Las colaterales axonales de las células piramidales y los axones de células intrínsecas muestran igualmente marcadas diferencias y contrastadas formas de conectarse con otros elementos dentro de la propia corteza y en función de su localización. Hemos mencionado que las células piramidales de las capas II y III proyectan fundamentalmente fibras de asociación homo y contralaterales. En su transcurso intracortical, los axones de estas células emiten colaterales ascendentes u horizontales que, en algunos casos, alcanzan distancias considerables; la rama descendente principal puede atravesar las capas medias sin emitirninguna colateral, pero sí hacerlo, o incluso finalizar, en las capas V o VI (Fig. 10, b y c), lo que indica una especificidad laminar bastante acusada. También mencionamos anteriormente que las células piramidales de proyección a centros subcorticales están situadas en las capas profundas, capas V (proyecciones al cuerpo estriado, tronco del encéfalo y tracto piramidal) y VI (probablemente a núcleos talámicos específicos y otros centros subcorticales). Numerosos estudios experimentales, que resultaría prolijo detallar, en los que las células piramidales han sido marcadas con distintas sustancias trazadoras, han revelado muchos datos relativos a patrones de ramificación, dendrítica y axonal, así como de los contactos sinápticos por ellas efectuados [54, 105,158,163,263,338,339,343]. Entre estos estu-

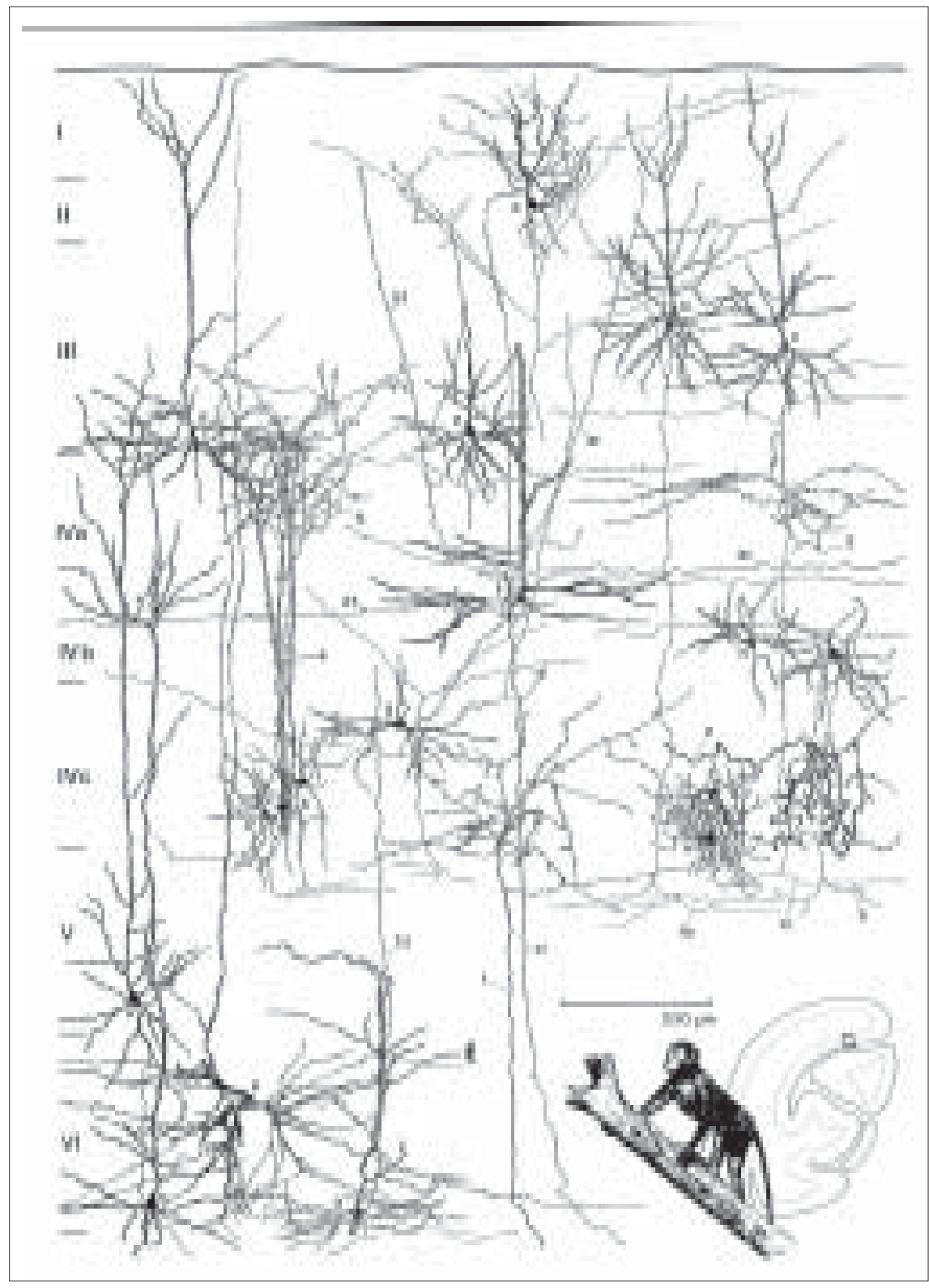

Figura 10. Circuitos intracorticales establecidos entre variedades celulares en la corteza visual del mono adulto (Macaca irus). Fibras aferentes corticales (1, 2, 3) se ramifican en las capas IVa y IVc. Ejemplos de células piramidales superficiales de las capas $I \mid$ y III (a-e) con axones distribuidos en la capa V (1b, 1c, pertenecientes a las células b y c, respectivamente). La célula f, en el centro de la imagen, corresponde a una célula piramidal de tamaño mediano de la capa IVb, estría de Gennari, con colaterales horizontales que alcanzan grandes distancias ( $2 f, 3 f)$ y otras oblicuamente ascendentes (4f, 5f). Las células g-i corresponden a variedades de células estrelladas con espinas; las células j-I representan el elemento caracteristico de células estrelladas con espinas y axones recurrentes, formando un fascículo (4) que finaliza (5) en la parte baja de la capa III y capa IVa. La célula m es una célula en ovillo. Las células piramidales de las capas profundas ( $\mathrm{V}$ y VI) están representadas por las células n-q, haciendo notar que los tallos apicales de algunas de ellas $(n, o, q)$ forman sus penachos terminales a distintas alturas, sin alcanzar la capa I. E esquema en la parte inferior derecha indica la región reproducida en este figura. Método de Golgi. Dibujo a la cámara clara. Tomada de [320] y reproducida con autorización de Pergamon Press.

dios es conveniente resaltar aquellos en los que se demostró la existencia de conexiones horizontales, dentro de la corteza, que pueden llegar a alcanzar varios milímetros $[37,45,85,86]$. Posteriores estudios revelaron la existencia de un complejo sistema de fibras, periódica y regularmente espaciadas, extendidas horizontalmente en las capas II y III, que tienen la apariencia de un patrón reticular semejante a una malla, fácilmente observado en cortes tangenciales de la corteza [19,156,262, 264,265], confirmándose, 


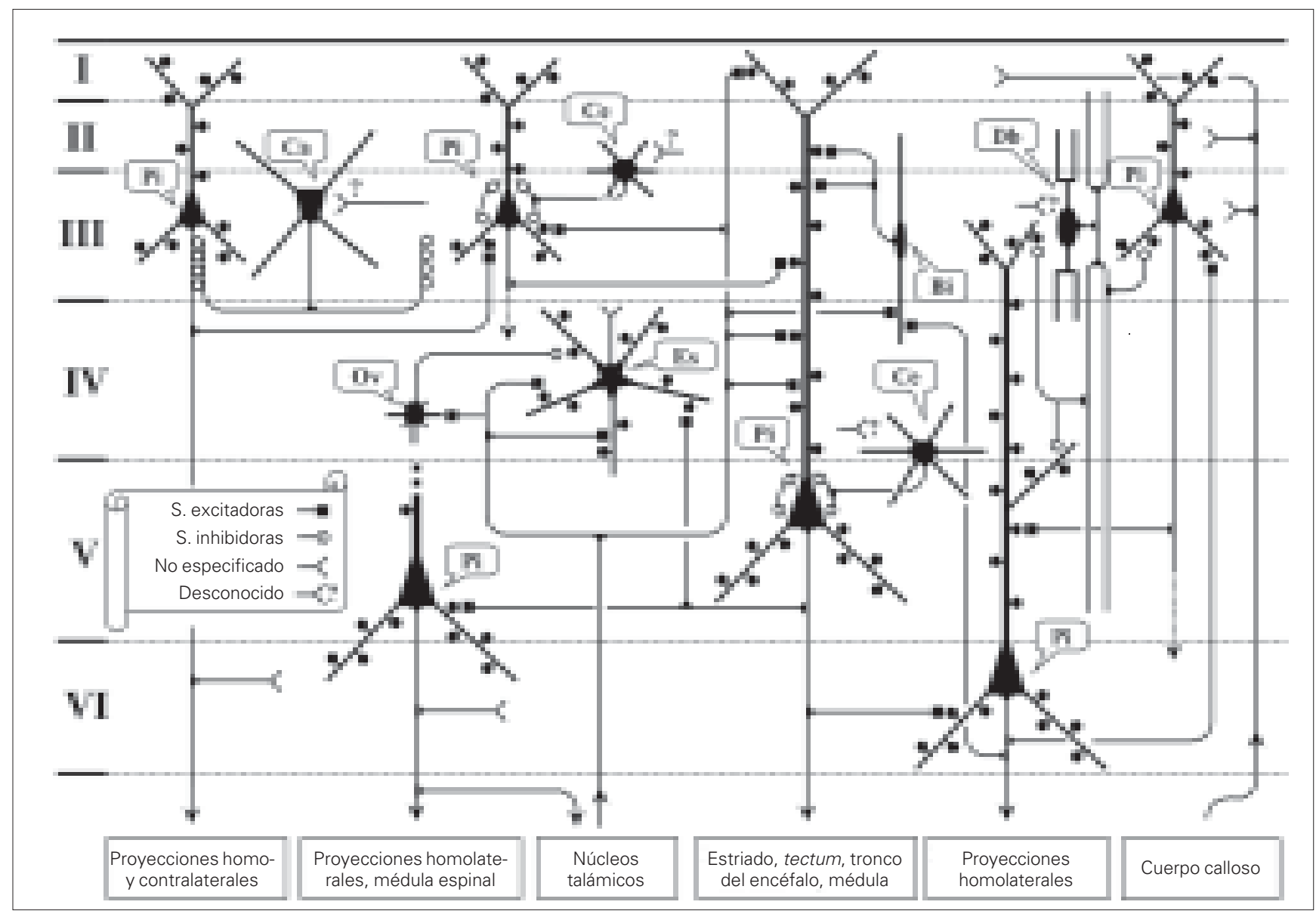

Figura 11. Esquema que representa las conexiones sinápticas entre varios tipos celulares establecidas de forma cierta, entendiendo con ello aquellas en las que ambos elementos pre y postsináptico han sido marcados en la misma preparación. Las sinapsis excitadoras aparecen señaladas con un cuadrado negro; las inhibidoras, como un círculo vacío. Para completar el esquema, se señalan de forma general, las proyecciones subcorticales y los sistema aferentes de diverso origen. Bi: células bipolares; Ca: células en candelabro; Ce: células en cesto; Db: células bipenachadas; Es: células estrelladas con espinas; Ov: células en ovillo; Pi: células piramidales.

por lo menos en el gato, que estas conexiones intrínsecas están, en parte, formadas por colaterales horizontales de los axones de células piramidales de las capas II y III, las cuales se ramifican en intervalos regularmente espaciados [106,188,189,202,203]. Nosotros hemos descrito, en la estría de Gennari de la corteza visual del mono (subcapa IVb), que no recibe fibras talámicas directas, un sistema de largas fibras horizontales formadas por colaterales de células piramidales superficiales y de las grandes células propias de la misma subcapa IVb [314,319] (Figs. 10,f, 2f y 3f), habiéndose confirmado posteriormente que este sistema de fibras horizontales también se ramifica a intervalos regulares que coinciden con las ramificaciones periódicas de las capas II y III [264].

Siempre dentro de una presunción lógica, suponemos que las colaterales axónicas de células piramidales de las capas superficiales II y III y profundas en las capas V y VI conectan con otras células piramidales situadas en las mismas capas, así como también con células estrelladas con espinas, a su paso por las capas medias de la corteza. Estas últimas pueden volver a conectar con las mismas células piramidales, formando así circuitos de retroalimentación. Algunas de estas conexiones entre células piramidales se han podido demostrar de forma convincente utilizando el marcador de peroxidasa de rábano o HRP [163,341].

En la figura 11 se muestra un esquema general de aquellas conexiones intracorticales que han podido ser demostradas de for- ma absoluta, entendiendo por ello aquellas en las que el elemento presináptico (célula y su terminación axonal) y el postsináptico (neurona receptora) han sido marcados e identificados en la misma preparación. En este esquema prescindimos de incluir algunas variedades neuronales (células de Cajal-Retzius de la capa I, células de axón ascendente, variedades de células de axón local) por no darse esta circunstancia o no estar claramente definidas, siendo posible que resulte incompleto o erróneo en algunos detalles. También hemos de señalar que, de forma orientativa, se hace referencia a las proyecciones subcorticales y otras aferencias corticales. El esquema está basado en nuestra propia recopilación bibliográfica y en revisiones de carácter específico [74,76,338]. Pensando que en la corteza cerebral humana se ha estimado que existen $3 \times 10^{14}$ sinapsis [35], que relacionan entre sí a una población compuesta por $1,5 \times 10^{10}$ neuronas [20], y en donde cada una de ellas recibe un promedio de 38.000 contactos sinápticos [43], nos daremos cuenta de lo que aún queda por conocer (nuestro esquema identifica de forma aleatoria 32 sinapsis y 13 neuronas).

\section{ORGANIZACIÓN MODULAR DE LA CORTEZA CEREBRAL}

La organización funcional de la corteza cerebral está basada en el concepto de unidad elemental propuesto por Lorente de Nó [187]. 
Este término fue, en principio, empleado para designar la conectividad intrínseca de la corteza dentro de un cilindro vertical, o columna que, teniendo por eje central la fibra aferente específica del tálamo, contiene, además, todos los elementos capaces de desarrollar el proceso completo de transmisión nerviosa desde la fibra aferente de entrada a la fibra de proyección cortical. Durante varios años, este concepto tuvo un significado funcional evidente, ya que explicaba los resultados obtenidos en neurofisiología en las áreas primarias somatosensorial [216,217], auditiva [1,140,356] y visual $[131,132,135]$; esto es, aquellas células que muestran idénticas propiedades funcionales aparecen dispuestas en una columna vertical que ocupa todo el espesor de la corteza. En el caso concreto de la corteza visual primaria [131,135] se encontró que las neuronas que responden a estímulos visuales (generalmente respuestas a formas simples de estímulos estacionarios dentro del campo visual) con una misma orientación están alineadas verticalmente en todo el espesor cortical (columnas de orientación), tras registrar su actividad atravesando las distintas capas corticales.

Hubel y Wiesel [133] obtuvieron la primera evidencia anatómica de una estructura cortical que pudiera estar relacionada con la organización en columnas funcionales en la corteza visual del mono (Macaca); estos investigadores, utilizando técnicas de impregnación argéntica, demostraron la existencia de un sistema de bandas alternantes de acuerdo con su origen en el núcleo geniculado lateral inervadas por una u otra retina (columnas de dominancia ocular), y que correspondían a la degeneración terminal producida tras lesionar específicamente distintas capas del núcleo geniculado lateral. Una de las imágenes más demostrativas de este agrupamiento columnar es la obtenida tras la inyección de un trazador radioactivo en un ojo en el macaco adulto, imagen que revela el aspecto del marcaje en forma de segmentos, de unas $400 \mu$ m de diámetro y separados por otros intervalos del mismo tamaño sin marcaje, que corresponden a la proyección a la capa IV del trazador radioactivo captado por el ojo inyectado [135] (Fig. 12). Posteriormente se comprobó la existencia de una estructuración similar en casi todas las áreas corticales, de forma que, con el desarrollo de nuevas técnicas para el trazado de vías, el uso de reacciones enzimáticas y trazadores radioactivos, se ha probado que la corteza cerebral está organizada en subdivisiones periódicas, regularmente espaciadas, que corresponden a la distribución topográfica de las fibras aferentes talámicas. Esto ha demostrado una correspondencia precisa entre la distribución de las fibras talámicas y patrones de representación cortical, tales como el campo de barriles (representación cortical de cada vibrisa) en la corteza somatosensorial del ratón y rata [334,358], las bandas de dominancia ocular en la corteza visual del mono [173], o la disposición radial de cadenas neuronales con las mismas características de respuesta a determinadas frecuencias de sonido en la corteza auditiva $[1,25]$. Estos sistemas de particiones ordenadas en módulos o columnas no son privativos de las áreas sensoriales primarias, pues se ha demostrado que las proyecciones corticocorticales (fibras callosas y de asociación) se distribuyen igualmente en bandas orientadas verticalmente y separadas de las correspondientes a las fibras aferentes talamocorticales [149,349,360]. Con la técnica de la 2-desoxi-glucosa, aquellas estructuras que han sido activadas funcionalmente pueden ser visualizadas por autorradiografía [284]. De esta forma, en monos con un ojo ocluido o enucleado, la retina del otro lado es capaz de provocar patrones de actividad en la corteza visual y mostrar el sistema columnar completo, desde la capa I hasta la sustancia blanca [160].

En el gato, las bandas o columnas de dominancia ocular se han manifestado tras la inyección de un marcador radioactivo en

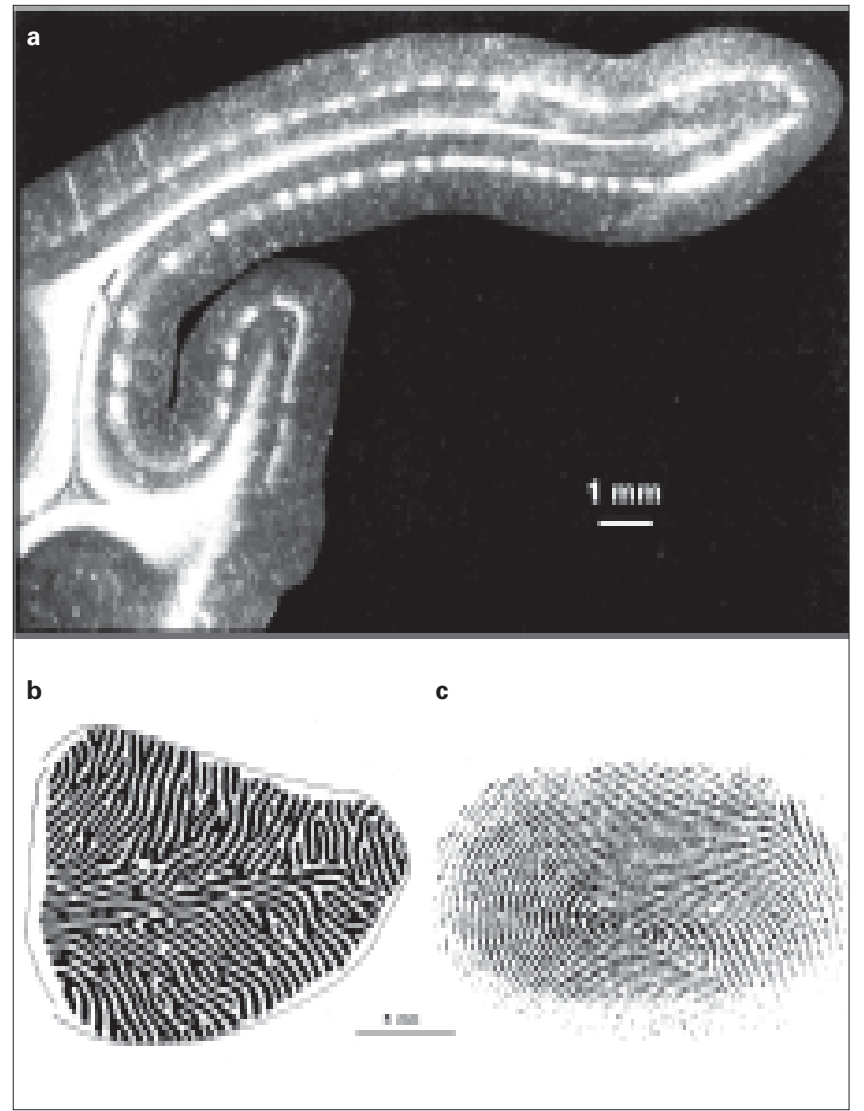

Figura 12. a) Columnas de dominancia ocular. Autorradiografía en campo oscuro de la corteza visual del mono en el que el ojo de un lado fue inyectado, dos semanas antes, con una mezcla de prolina tritiada y fucosa. El compuesto radioactivo es captado por las células de las correspondientes capas del núcleo geniculado lateral y transportado por sus axones a la corteza visual, en donde se muestran como bandas discontinuas en la capa IVc, de aproximadamente 0,4 mm, y separadas por espacios sin marcar y del mismo tamaño, que corresponden a las bandas en donde proyectan las capas del núcleo geniculado que reciben las conexiones de ojo no inyectado; b) Reconstrucción completa de las bandas de dominancia ocular en la capa IVc en toda la superficie expuesta de la corteza visua del mono, obtenida de cortes seriados teñidos por la plata reducida; cl Imagen de una huella dactilar humana a la misma escala que ' $b$ '. Imágenes tomadas de [135] y reproducidas por cortesía del Dr. Wiesel, y con autorización de Cambridge University Press.

un ojo [175,219,280,281], empleando la técnica de la 2-desoxiglucosa [308], o bien inyectando en un ojo aglutinina del germen de trigo conjugada con peroxidasa de rábano, apareciendo similares a las del mono, pero más irregulares, menos finamente organizadas y, además, continuando en el área 18 (área visual secundaria), en donde se muestran con una anchura doble [280]. Experimentos electrofisiológicos paralelos confirmaron que las bandas de dominancia ocular coinciden con las bandas de orientación [175,281]. En otros carnívoros, como el visón [174,205] y el hurón [167], las bandas de dominancia ocular se han observado anatómica y fisiológicamente.

Los estudios sobre la organización columnar en la corteza también se han visto favorecidos con la utilización de varias técnicas histoquímicas capaces de mostrar un mapa de la actividad funcional en áreas cerebrales localizadas. En este sentido, uno de los aspectos más interesantes de organización funcional ha sido revelado por el uso de la técnica de la citocromo oxidasa. Empleando esta técnica, se demostró que el nivel de actividad varía en diferentes regiones, aumentando en zonas metabólicamente activas o dis- 
minuyendo en zonas de bajo nivel de actividad [350,353], y con la ventaja de que la técnica revela cambios producidos durante largo tiempo, circunstancia que ha sido aprovechada, por ejemplo, para obtener un mapa de las columnas de dominancia ocular en el cerebro humano en casos de muerte acaecida largo tiempo después de la pérdida de un ojo [128]. Así pues, en experimentos llevados a cabo en gatos, en los que se había practicado una sutura palpebral o en los que se había procedido a la enucleación de un ojo, se demostró la existencia de un patrón columnar en la corteza visual, muy similar al obtenido en el mono [351]. No obstante, el interés en el empleo de esta técnica aumentó considerablemente cuando se descubrió que en las capas superficiales II y III de la corteza visual primaria del macaco, la enzima revela la presencia de un mosaico de manchas regulares en forma de burbujas (blobs) dispuestos en hileras paralelas y centrados exactamente sobre las bandas de dominancia ocular [12,30,116,127,130,136]. El patrón bidimensional de burbujas o blobs observado mediante esta técnica contiene células que muestran una fuerte preferencia por los estímulos recibidos de una u otra retina $[30,116,127,130,136]$, recibiendo proyecciones directas del núcleo geniculado lateral [87,182,183,333].

¿Cuál es el significado funcional de toda esta organización modular de la corteza? En cuanto a la corteza visual se refiere, la existencia de las bandas o columnas de dominancia ocular está obviamente relacionada con la segregación, en la corteza, de los impulsos recibidos de la retina de cada ojo, en aquellos animales que tienen una decusación parcial de las fibras ópticas y cuerpo geniculado estratificado en capas. Están probablemente implicadas en la visión tridimensional y representan un mecanismo por medio del cual pueden procesarse distintas variables combinando la entrada captada por cada retina en columnas o bandas complementarias en una superficie estructurada en dos dimensiones, como es la corteza cerebral [132,135,170,173]. La segregación de las bandas durante el desarrollo implica, probablemente, la eliminación de colaterales talámicas inapropiadas, o el crecimiento de ramas axónicas terminales en determinadas direcciones, entre otros. Algunos de estos mecanismos no están aún aclarados del todo, pero lo que sí parece cierto es que la segregación en bandas alternas para cada ojo durante el desarrollo es un proceso específico de la propia corteza o de las fibras aferentes talámicas (proyecciones del núcleo geniculado lateral), ya que la eliminación temprana de las proyecciones que vienen de la retina de un lado no afectan esta segregación $[47,129]$. La organización en bandas de dominancia ocular no depende tampoco de la actividad visual [299]. En resumen, puede decirse que, en general, la estructura básica de la corteza cerebral es innata, y la actividad es esencial para su correcto mantenimiento; manipulaciones experimentales (enucleación, deprivación visual, etc.) o alteraciones patológicas del entorno visual (ceguera congénita, estrabismo, anisometropía, etc.) sólo producen variaciones en determinados parámetros como el ancho, número de bandas, periodicidad y otras alteraciones que, aunque fácilmente detectables, nunca implican su total anulación [44,129,135,176,219].

Se ha sugerido que el patrón de burbujas revelado por la técnica de la citocromo oxidasa podría estar implicado en la percepción del color $[183,184]$, y probablemente relacionado con circuitos intracorticales inhibidores [116,283,354,355]. Las burbujas contienen células con distintas conexiones (incluso a otras áreas secundarias) y diferentes propiedades funcionales [22,67, 72,78,352] pero, en cualquier caso, su empleo ha sido de gran ayuda como marcador efectivo de la organización columnar de la corteza visual y, por extensión, en el resto de las áreas corticales. El agrupamiento de las células de la corteza en unidades anatomofuncionales representa un primer paso en procesos de análisis mucho más complejos. Obviamente las neuronas de la corteza visual no están diseñadas sólo para detectar barras de distinta orientación, lo mismo que las células en el área somatosensorial de roedores tampoco lo están para reconocer movimientos de las vibrisas, sino como proceso previo para análisis mucho más complejos en los que intervienen múltiples áreas secundarias capaces de elaborar las respuestas adecuadas.

\section{CONCLUSIONES}

En los últimos años hemos sido testigos de una nueva área de investigación relativa al estudio de los diversos genes que controlan los procesos de especificación cortical y de conectividad neuronal [6-8,68,268]. El estudio de la expresión de estos genes está aportando nuevos datos relativos a la posibilidad de identificar características que han permanecido constantes a lo largo de la evolución y averiguar hasta qué punto varios tipos celulares y sus procesos dendríticos y axonales difieren entre las distintas especies [155].

¿Existe un plan básico de organización cortical ? El neocórtex, en general, no muestra una estructura uniforme, sino que contiene un número de áreas corticales que pueden ser distinguidas por características anatómicas y funcionales diferentes. Hemos revisado los aspectos más sobresalientes de la organización de la corteza cerebral, comprobando que el neocórtex aparece uniforme a un nivel de organización elemental; no obstante, el estudio de las fibras aferentes corticales, las variedades neuronales y la forma de conectarse entre ellas, indican claramente la existencia de variaciones, algunas de las cuales podrían ser únicas para una determinada especie. Entre ellas destacamos: las células estrelladas con espinas típicas de la corteza somatosensorial de roedores, células estrelladas con espinas y axón recurrente, aparentemente singulares en el cerebro de primates, células estrelladas con espinas y axón de proyección a la sustancia blanca en la corteza visual de carnívoros, células piramidales especiales en la capa II en insectívoros, por mencionar algunos ejemplos que, considerados individualmente, pueden no tener equivalente en otras especies y que pueden ser un buen ejemplo de evolución. Varios argumentos sugieren que el cerebro de los mamíferos más evolucionados se configuró a partir de un cerebro primitivo exclusivamente olfativo $[9,121,147]$, que fue posteriormente invadido por nuevas modalidades sensoriales, pero este concepto ha sido revisado recientemente y se ha sugerido que la hipótesis de la 'invasión' no operó durante la evolución, sino que los sistema neurales, en general, y la corteza cerebral, en particular, se desarrollaron por diferenciación y parcelación, lo que implica mecanismos de competición y redistribución de los impulsos aferentes, así como la pérdida selectiva de determinadas conexiones [70]. Nuestro punto de vista está de acuerdo con esta teoría.

En nuestros estudios sobre el cerebro del erizo (Erinaceus europaeus), hemos destacado la gran extensión de las estructuras olfativas y la presencia de un neocórtex muy reducido. En esta especie, la capa I del neocórtex es de un espesor considerable, y recibe numerosas fibras aferentes de núcleos talámicos específicos, dendritas apicales de células piramidales de capas inferiores y gran cantidad de dendritas ascendentes de células piramidales de la capa II [322,326,327]. Estas características destacadas en la zona marginal (capa I) indican la preservación de una organización especial, mediante la cual fibras aferentes de largo recorrido horizontal son capaces de efectuar contactos sobre el mayor número posible de células, siendo en todo similar a la organización de la corteza olfativa. La diferenciación evolutiva del neocórtex está, posible- 
mente, relacionada con el cambio en la distribución de estas fibras aferentes corticales que, de la capa I (allocortex y paleocortex), y por extensión, homóloga a la estructura de la corteza dorsal de reptiles [307], acabaron predominando en las capas medias de la corteza (parte baja de la capa III y capa IV), siendo el erizo un testigo intermedio en este cambio. No existen razones que expliquen de una forma convincente cómo se han producido estas variaciones a lo largo de la evolución [2,153,223], si bien, para su explicación, se ha recurrido a mecanismos moleculares [4,213,267], embriológicos [42,296,297] y genéticos [3,10,11,122,250], entre otros; pero lo que sí parece cierto es que esta progresiva modificación varió la organización intrínseca de la corteza cerebral, desde una organización laminar (fibras aferentes a la capa molecular, capa I), hasta una estructura columnar, como la descrita en el apartado precedente. Estas modificaciones implicaron notables variaciones en las neuronas receptoras de las fibras aferentes específicas, como pensamos que ha ocurrido, por ejemplo, con las células estrelladas con espinas en la corteza visual de los primates. A pesar de que estas células no proyectan a la sustancia blanca, su morfo- logía recuerda a la de una célula piramidal con tallo apical truncado o ausente [191], por lo que se han considerado el resultado de una transformación evolutiva de las células piramidales [321], probablemente en relación con los cambios mencionados sobre la distribución de las fibras aferentes corticales, predominantes en la capa I en mamíferos primitivos (insectívoros), hacia su distribución en las capas medias del neocórtex [298,321]. De esta forma, en el estudio de la morfología de los diferentes tipos de células estrelladas con espinas en varios mamíferos, siempre tuvimos la impresión de que todas ellas comparten un origen común y que puede ser trazado un continuo a lo largo de la escala filogenética, variaciones que, evidentemente, implican una notable modificación de la organización intrínseca neocortical durante la evolución [321]. Nosotros hemos puesto énfasis en la consideración de estos datos, ya que entendemos que la multiplicación de arquetipos modulares en la corteza, sugerida en varios estudios [108,273] para explicar la evolución del neocórtex, no considera la diversidad de variedades neuronales encontradas en diferentes clases de mamíferos, algunas de las cuales pueden ser únicas cuando se comparan distintas especies.

\section{BIBLIOGRAFÍA}

1. Abeles M, Goldstein MH. Functional architecture in cat primary auditory cortex. Columnar organization and organization according to depth. J Neurophysiol 1970; 33: 172-87.

2. Aboitiz F. Homology in the evolution of the cerebral hemispheres. The case of reptilian dorsal ventricular ridge and its possible correspondence with mammalian neocortex. J Hirnforsch 1995; 36: 461-72.

3. Aboitiz F. Evolution of isocortical formation. A tentative scenario including roles of reelin, p35/cdk5 and the subplate zone. Cereb Cortex 1999; 9: 655-61.

4. Allendoerfer KI, Shatz CJ. The subplate, a transient neocortical structure: its role in the development of connections between thalamus and cortex. Ann Rev Neurosci 1994; 17: 185-218.

5. Anderson B, Rutledge V. Age and hemisphere effects on dendritic structure. Brain 1996; 119: 1983-90.

6. Anderson SA, Eisenstat DD, Shi L, Rubenstein JLR. Interneuron migration from basal forebrain to neocortex: dependence on Dlx genes. Science 1997a; 278: 474-6.

7. Anderson SA, Qiu M-S, Bulfone A, Eisenstat DD, Meneses J, Pedersen $\mathrm{R}$, et al. Mutation of the homeobox genes Dlx-1 and Dlx-2 disrupt the striatal subventricular zone and differentiation of late-born striatal neurons. Neuron 1997b; 19: 27-37.

8. Anderson SA, Mione M, Yun K, Rubenstein JLR. Differential origins of neocortical projection and local circuit neurons: role of Dlx genes in neocortical neurogenesis. Cereb Cortex 1999; 9: 646-54.

9. Ariëns Kappers CU, Huber GC, Crosby EC. The comparative anatomy of the nervous system of vertebrates, including man. New York: Ed. Hafner; 1936.

10. Bar I, Goffinet AM. Evolution of cortical lamination: the reelin/Dab1 pathway. Novartis Found Symp 2000; 228: 114-25.

11. Bar I, Lambert de Rouvroit C, Goffinet AM. The evolution of cortical development. An hypothesis based on the role of the reelin signaling pathway. Trends Neurosci 2000; 23: 633-8.

12. Bartfeld E, Grinvald A. Relationships between orientation-preference pinwheels, cytochrome oxidase blobs, and ocular-dominance columns in primate striate cortex. Proc Natl Acad Sci U S A 1992; 89: 11905-9.

13. Bekenstein JW, Lothman EW. Dormancy of inhibitory interneurons in a model of temporal lobe epilepsy. Science 1993; 259: 97-100.

14. Bernard C, Esclapez M, Hirsch JC, Ben-Ari Y. Interneurones are not so dormant in temporal lobe epilepsy: a critical reappraisal of the dormant basket cell hypothesis. Epilepsy Res 1998; 32: 93-103.

15. Betz W. Anatomischer Nachweis zweier Gehirnzentra. Zentralbl Med Wiss $1874 ; 12: 578-80$.

16. Blakemore C, Vital-Durand F. Distribution of X-and Y-cells in the monkey's lateral geniculate nucleus. J Physiol 1981; 320: 17-8P.

17. Blakemore C, Vital-Durand F. Organization and postnatal development of the monkey's lateral geniculate nucleus. J Physiol 1986; 380 : 453-91.

18. Blasdel GG, Lund JS. Termination of afferent axons in macaque striate cortex. J Neurosci 1983; 3: 1389-413.

19. Blasdel GG, Lund JS, Fitzpatrick D. Intrinsic connections of macaque striate cortex: axonal projections of cells outside lamina 4C. J Neurosci $1985 ; 5: 3350-69$.
20. Blinkov SM, Glezer II. The human brain in figures and tables. A quantitative handbook. New York: Ed. Plenum Press; 1978.

21. Bode-Greuel KM, Singer W, Aldenhoff JB. A current source density analysis of field potentials evoked in slices of visual cortex. Exp Brain Res 1987; 69: 213-9.

22. Boyd JD, Casagrande VA. Relationship between cytochrome oxidase (CO) blobs in primate primary visual cortex (V1) and the distribution of neurons projecting to the middle temporal area (MT). J Comp Neurol 1999; 409: 573-91.

23. Brodmann K. Beiträge zur histologischen Lokalisation der Grosshirnrinde. Zweite Mitteilung: Der Calcarinatypus. J Physiol Neurol (Leipzig) 1903-1904; 2: 133-59.

24. Brodmann K. Vergleichende Lokalisationslehre der Grosshirnrinde. Leipzig: Ed. Barth; 1909.

25. Brugge JF, Reale RA. Auditory cortex. In Peters A, Jones EG, eds. Cerebral cortex. Vol. 4. Association and auditory cortices. New York: Ed. Plenum Press; 1985. p. 229-71.

26. Bugbee NM, Goldman-Rakic PS. Columnar organization of corticocortical projections in squirrel and rhesus monkey: similarity of column width in species differing in cortical volume. J Comp Neurol 1983; 220: 355-64.

27. Bullier J, Henry GH. Laminar distribution of first order neurons and afferent terminals in cat striate cortex. J Neurophysiol 1979; 42: 1271-81.

28. Butler AB. Cytoarchitectonic and connectional organization of the lacertilian telencephalon with comments on vertebrate forebrain evolution. In Ebbesson SOE, ed. Comparative neurology of the telencephalon. New York: Ed. Plenum Press; 1980. p. 297-329.

29. Callaway EM. Local circuits in primary visual cortex of the macaque monkey. Ann Rev Neurosci 1998; 21: 47-74.

30. Carroll EW, Wong-Riley MTT. Quantitative light and electron microscopic analysis of cytochrome oxidase-rich zones in the striate cortex of the squirrel monkey. J Comp Neurol 1984; 222: 1-17.

31. Casagrande VA. A third parallel visual pathway to primate area V1. Trends Neurosci 1994; 17: 305-10.

32. Chang HT. Cortical neurons with particular reference to the apical dendrites. Cold Spring Harb Symp Quant Biol 1952; 17: 189-202.

33. Cipolloni PB, Peters A. The termination of callosal fibers in the auditory cortex of the rat. A combined Golgi-electron microscope and degeneration study. J Neurocytol 1983; 12: 713-26.

34. Colonnier M. Synaptic patterns on different cell types in the different laminae of the cat visual cortex: an electron microscope study. Brain Res 1968; 9: 268-87.

35. Colonnier M. The electron-microscopic analysis of the neuronal organization of the cerebral cortex. In Schmitt FO, Worden FG, Adelman $\mathrm{G}$, Dennis SG, eds. The organization of the cerebral cortex. Cambridge, Massachusetts: Ed. MIT Press; 1981. p. 125-52

36. Colonnier M, Rossignol S. Heterogeneity of the cerebral cortex. In Jasper H, Ward A, Pope A, eds. Basic mechanisms of the epilepsies. Boston: Ed. Little Brown; 1969. p. 29-40.

37. Colonnier M, Sas E. An anterograde degeneration study of the tangential spread of axons in cortical areas 17 and 18 of the squirrel monkey (Saimiri sciureus). J Comp Neurol 1978; 179: 245-62.

38. Conley M, Fitzpatrick D, Diamond IT. The laminar organization of the 
lateral geniculate body and the striate cortex in the tree shrew (Tupaia glis). J Neurosci 1984; 4: 171-97.

39. Conti F, de Felipe J, Fariñas I, Manzoni T. Glutamate-positive neurons and axon terminals in cat sensory cortex: a correlative light and electron microscopic study. J Comp Neurol 1989; 290: 141-53.

40. Conti F, Fabri M, Manzoni T. Glutamate-positive cortico-cortical neurons in the somatic sensory areas I and II of cats. J Neurosci 1988; 8: 2948-60.

41. Conti F, Rustioni A, Petrusz P, Towle AC. Glutamate-positive neurons in the somatic sensory cortex of rats and monkeys. J Neurosci 1987; 7: 1887-901.

42. Cordery P, Molnár Z. Embryonic development of connections in turtle pallium. J Comp Neurol 1999; 413: 26-54.

43. Cragg BG. The density of synapses and neurons in normal, mentally defective and ageing human brains. Brain 1975; 98: 81-90.

44. Crair MC, Gillespie DC, Stryker MP. The role of visual experience in the development of columns in cat visual cortex. Science 1998; 279: 566-70.

45. Creutzfeldt OD, Garey LJ, Kuroda R, Wolf J-R. The distribution of degenerating axons after small lesions in the intact and isolateral visual cortex of the cat. Exp Brain Res 1975; 27: 419-40.

46. Crick F. Do dendritic spines twitch? Trends Neurosci 1982; 5: 44-6.

47. Crowley JC, Katz LC. Development of ocular dominance columns in the absence of retinal input. Nature Neurosci 1999; 2: 1125-30.

48. Czeiger D, White EL. Synapses of extrinsic and intrinsic origin made by callosal projection neurons in mouse visual cortex. J Comp Neurol 1993; 330: 502-13.

49. Davis TL, Sterling P. Microcircuitry of cat visual cortex: classification of neurons in layer IV of area 17, and identification of the patterns of lateral geniculate input. J Comp Neurol 1979; 188: 599-628.

50. De Carlos JA, López-Mascaraque L, Ramón y Cajal-Agüeras S, Valverde $\mathrm{F}$. Chandelier cells in the auditory cortex of monkey and man: a Golgi study. Exp Brain Res 1987; 66: 295-392.

51. De Carlos JA, López-Mascaraque L, Valverde F. Development, morphology and topography of chandelier cells in the auditory cortex of the cat. Dev Brain Res 1985; 22: 293-300.

52. De Carlos JA, López-Mascaraque L, Valverde F. Dynamics of cell migration from the lateral ganglionic eminence in the rat. J Neurosci 1996; 16: 6146-56.

53. De Felipe J. Chandelier cells and epilepsy. Brain 1999; 122: 1807-22.

54. De Felipe J, Conley M, Jones EG. Long-range focal collateralization of axons arising from corticocortical cells in monkey sensory-motor cortex. J Neurosci 1986; 6: 3749-66.

55. De Felipe J, Conti F, van Eyck SL, Manzoni T. Demonstration of glutamate-positive axon terminals forming asymmetric synapses in cat neocortex. Brain Res 1988; 455: 162-5.

56. De Felipe J, Fariñas I. The pyramidal neuron of the cerebral cortex: morphological and chemical characteristics of the synaptic inputs. Progress Neurobiol 1992; 39: 563-607.

57. De Felipe J, Hendry SHC, Jones EG. Visualization of chandelier cell axons by parvalbumin immunoreactivity in monkey cerebral cortex. Proc Natl Acad Sci U S A 1989; 86: 2093-7.

58. De Felipe J, Hendry SHC, Jones EG, Schmechel D. Variability in the termination of GABAergic chandelier cell axons on initial segments of pyramidal cell axons in the monkey sensory-motor cortex. J Comp Neurol 1985; 231: 364-84.

59. De Felipe J, Jones EG. High resolution light and electron microscopic immunocytochemistry of co-localized GABA and calbindin D-28k in somata and double bouquet cell axons of monkey somatosensory cortex. Eur J Neurosci 1992; 4: 46-60.

60. De Felipe J, Segura T, Arellano JI, Merchán A, de Felipe-Oroquieta J, Martín P, et al. Neuropathological findings in a patient with epilepsy and the Parry-Romberg syndrome. Epilepsia 2001; 42: 1198-203.

61. del Río MR, de Felipe J. A light and electron microscopic study of calbindin D-28k immunoreactive double bouquet cells in the human temporal cortex. Brain Res 1995; 690: 133-40.

62. del Río MR, de Felipe J. Double bouquet cell axons in the human temporal neocortex: relationship to bundles of myelinated axons and colocalization of calretinin and calbindin D-28k immunoreactivities. J Chem Neuroanat 1997; 13: 243-51

63. de Robertis E, Bennett HS. Submicroscopic vesicular component in the synapse. Fed Proc 1954; 13: 35.

64. Derrington AM, Lennie P. Spatial and temporal contrast sensitivities of neurons in the lateral geniculate nucleus of macaque. J Physiol 1984; 357: $219-40$.

65. Diamond IT, Conley M, Itoh K, Fitzpatrick D. Laminar organization of geniculocortical projections in Galago senegalensis and Aotus trivirgatus. J Comp Neurol 1985; 242: 584-610.

66. Diamond J, Gray EG, Yasargil EN. The function of dendritic spines: an hypothesis. In Anderson P, Jansen JKS, eds. Excitatory synaptic mechanisms. Oslo: Ed. Universitetsforlaget; 1970. p. 213-22.

67. Ding Y, Casagrande VA. Synaptic and neurochemical characterization of parallel pathways to cytochrome oxidase blobs of primate visual cortex. J Comp Neurol 1998; 391: 429-43.

68. Donoghue MJ, Rakic P. Molecular evidence for the early specification of presumptive functional domains in the embryonic primate cerebral cortex. J Neurosci 1999; 19: 5967-79.

69. Dreher B, Fukuda Y, Rodieck RW. Identification, classification and anatomical segregation of cells with $\mathrm{X}$-like and Y-like properties in the lateral geniculate nucleus of Old-World primates. J Physiol 1976; 258: 433-52.

70. Ebbesson SOE. The parcellation theory and its relation to interspecific variability in brain organization, evolutionary and ontogenetic development, and neural plasticity. Cell Tissue Res 1980; 213: 179-212.

71. Eccles JC. The modular operation of the cerebral cortex considered as the material basis of mental events. Neuroscience 1984; 6: 1839-56.

72. Edwards DP, Purpura KP, Kaplan E. Contrast sensitivity and spatial frequency response of primate cortical neurons in and around the cytochrome oxidase blobs. Vis Res 1995; 35: 1501-23.

73. Elston GN, Tweedale R, Rosa MGP. Cortical integration in the visual system of the macaque monkey: large scale morphological differences of pyramidal neurons in the occipital, parietal and temporal lobes. Proc Roy Soc Lond B 1999; 266: 1367-74.

74. Fairén A, de Felipe J, Regidor J. Nonpyramidal neurons. General account. In Peters A, Jones EG, eds. Cerebral cortex. Vol. 1. Cellular components of the cerebral cortex. New York: Ed. Plenum Press; 1984. p. 201-53.

75. Fairén A, Peters A, Saldanha J. A new procedure for examining Golgi impregnated neurons by light and electron microscopy. J Neurocytol 1977; 6: 311-37

76. Fairén A, Valverde F. Specific thalamo-cortical afferents and their presumptive targets in the visual cortex. A Golgi study. In Cuénod M, Kreutzberg GW, Bloom FW, eds. Progress in brain research. Development and specificity of neurons. Vol. 51. Amsterdam: Ed. Elsevier; 1979. p. 419-38.

77. Fairén A, Valverde F. A specialized type of neuron in the visual cortex of cat: a Golgi and electron microscope study of chandelier cells. J Comp Neurol 1980; 194: 761-79.

78. Farias MF, Gattass R, Pinon MC, Ungerleider LG. Tangential distribution of cytochrome oxidase-rich blobs in the primary visual cortex of macaque monkeys. J Comp Neurol 1997; 386: 217-28.

79. Feldman ML, Peters A. The form of non-pyramidal neurons in the visual cortex of the rat. J Comp Neurol 1978; 179: 761-94.

80. Ferster D. X-and Y-mediated synaptic potentials in neurons of areas 17 and 18 of cat visual cortex. Vis Neurosci 1990a; 4: 115-33.

81. Ferster D. X-and Y-mediated current sources in areas 17 and 18 of cat visual cortex. Vis Neurosci 1990b; 4: 135-45.

82. Ferster D, LeVay S. The axonal arborizations of lateral geniculate neurons in the striate cortex of the rat. J Comp Neurol 1978; 182: 923-44.

83. Fifková E, Delay RJ. Cytoplasmic actin in neuronal processes as a possible mediator in synaptic plasticity. J Cell Biol 1982; 95: 345-50.

84. Fischer M, Kaech S, Wagner U, Brinkhaus H, Matus A. Glutamate receptors regulate actin-based plasticity in dendritic spines. Nat Neurosci 2000; 3: 887-94.

85. Fisken RA, Garey LJ, Powell TPS. Patterns of degeneration after intrinsic lesions of the visual cortex (area 17) of the monkey. Brain Res 1973; 53: 208-13.

86. Fisken RA, Garey LJ, Powell TPS. The intrinsic, association and commissural connections of area 17 of the visual cortex. Phil Trans R Soc Lond B 1975; 272: 487-536.

87. Fitzpatrick D, Itoh K, Diamond IT. The laminar organization of the lateral geniculate body and the striate cortex in the squirrel monkey (Saimiri sciureus). J Neurosci 1983; 3: 673-702.

88. Florence SL, Sesma MA, Casagrande VA. Morphology of geniculo-striate afferents in a prosimian primate. Brain Res 1983;270: 127-30.

89. Fonseca M, Soriano E, Ferrer I, Martínez A, Tuñón T. Chandelier cells axons identified by parvalbumin-immunoreactivity in the normal human temporal cortex and in Alzheimer's disease. Neuroscience 1993; 55: 1107-16.

90. Freund TF, Maglóczky ZS, Soltész I, Somogyi P. Synaptic connections, axonal and dendritic patterns of neurons immunoreactive for cholecystokinin in the visual cortex of the cat. Neuroscience 1986; 19: 1133-59.

91. Freund TF, Martin KAC, Smith AD, Somogyi P. Glutamate decarboxylase-immunoreactive terminals of Golgi-impregnated axoaxonic cells and of presumed basket cells in synaptic contact with pyramidal neurons of cat's visual cortex. J Comp Neurol 1983; 221: 263-78.

92. Freund TF, Martin KAC, Somogyi P, Whitteridge D. Innervation of cat visual areas 17 and 18 by physiologically identified X-and Y-type thalamic afferents. II. Identification of postsynaptic targets by GABA immunocytochemistry and Golgi impregnation. J Comp Neurol 1985a; 242: 275-91.

93. Freund TF, Martin KAC, Whitteridge D. Innervation of cat visual areas 17 and 18 by physiologically identified X-and Y-type thalamic afferents. I. Arborization patterns and quantitative distribution of postsynaptic elements. J Comp Neurol 1985b; 242: 263-74. 
94. Frick A, Zieglgänsberger W, Dodt H-U. Glutamate receptors form hot spots on apical dendrites of neocortical pyramidal neurons. J Neurophysiol 2001; 86: 1412-21.

95. Frost DO, Caviness VS. Radial organization of thalamic projections to the neocortex in the mouse. J Comp Neurol 1980; 194: 369-93.

96. Fujita I, Fujita T. Intrinsic connections in the macaque inferior temporal cortex. J Comp Neurol 1996; 368: 467-86.

97. Garey LH. A light and electron microscopic study of the visual cortex of the cat and monkey. Proc Roy Soc Lond B 1971; 179: 21-40.

98. Garey LH, Dreher B, Robinson SR. The organization of the visual thalamus. In Dreher B, Robinson SR, eds. Neuroanatomy of the visual pathways and their development. Vision and visual disfunction. Vol. 3. Basingstoke: Ed. MacMillan Press; 1991. p. 176-234.

99. Garey LJ, Ong WY, Patel TS, Kanani M, Davis A, Mortimer AM, et al. Reduced dendritic spine density on cerebral cortical pyramidal neurons in schizophrenia. J Neurol Neurosurg Psychiatry 1998; 65: 446-53.

100. Garey LH, Powell TPS. An experimental study of the termination of the lateral geniculo-cortical pathway in the cat and monkey. Proc Roy Soc Lond B 1971; 179: 1-63.

101. Geinisman Y. Structural synaptic modifications associated with hippocampal LTP and behavioral learning. Cereb Cortex 2000; 10: 952-62.

102. Geinisman Y, Berry RW, Disterhoft JF, Power JM, van der Zee ES Associative learning elicits the formation of multiple-synapse boutons. J Neurosci 2001; 21: 5568-73.

103. Gilbert CD. Microcircuitry of the visual cortex. Ann Rev Neurosci 1983; 6: 217-47.

104. Gilbert CD, Kelly JP. The projections of cells in different layers of the cat's visual cortex. J Comp Neurol 1975; 163: 81-106.

105. Gilbert CD, Wiesel TN. Morphology of intracortical projections of functionally characterised neurones in the cat visual cortex. Nature 1979; 280: $120-5$.

106. Gilbert CD, Wiesel TN. Clustered intrinsic connections in cat visual cortex. J Neurosci 1983; 3: 1116-33.

107. Glantz LA, Lewis DA. Decreased dendritic spine density on prefrontal cortical pyramidal neurons in schizophrenia. Arch Gen Psychiat 2000; 57: $65-73$

108. Glezer II, Jacobs MS, Morgane PJ. Implications of the 'initial brain' concept for brain evolution in Cetacea. Behav Brain Sci 1988; 11: 75-116.

109. Goldman-Rakic PS, Nauta WJH. Columnar distribution of cortico-cortical fibres in the frontal association, limbic and motor cortex of the developing rhesus monkey. Brain Res 1977; 122: 393-414.

110. Gould E, Reeves AJ, Graziano MSA, Gross CG. Neurogenesis in the neocortex of adult primates. Science 1999; 286: 548-52.

111. Gould JJ, Hall WC, Ebner FF. Connections of the visual cortex in the hedgehog (Paraechinus hypomelas). I. Thalamocortical projections. J Comp Neurol 1978; 177: 445-71.

112. Gray EG. Rehabilitating the dendritic spines. Trends Neurosci 1982; 5: 5-6.

113. Guillery RW. A study of Golgi preparations from the dorsal lateral geniculate nucleus of the adult cat. J Comp Neurol 1966; 128: 21-30.

114. Halpain S. Actin and the agile spine: how and why do dendritic spines dance? Trends Neurosci 2000; 23: 141-5.

115. Hasbani MJ, Schlief ML, Fisher DA, Goldberg MP. Dendritic spines lost during glutamate receptor activation reemerge at original sites of synaptic contact. J Neurosci 2001; 21: 2393-403.

116. Hendrikson AE, Hunt SP, Wu J-Y. Immunocytochemical localization of glutamic acid decarboxylase in monkey striate cortex. Nature 1981; 292: 605-7.

117. Hendrikson AE, van Brederode JFM, Mulligan KA, Celio MR. Development of the calcium-binding proteins parvalbumin and calbindin in monkey striate cortex. J Comp Neurol 1991; 307: 626-46.

118. Hendrickson AE, Wilson JR, Ogren MP. The neuroanatomical organization of pathways between the dorsal lateral geniculate nucleus and visual cortex in Old World and New World primates. J Comp Neurol 1978; 182: 123-36

119. Hendry SHC, Jones EG, Emson PC, Lawson DEM, Heizmann CW, Streit P. Two classes of cortical GABA neurons defined by differential calcium binding protein immunoreactivity. Exp Brain Res 1989; 76: 467-72.

120. Herkenham M. Laminar organization of thalamic projections to the rat neocortex. Science 1980; 207: 532-5.

121. Herrick CJ. A sketch of the origin of the cerebral hemispheres. J Comp Neurol 1920; 32: 429-54.

122. Hevner RF, Shi L, Justice N, Hsueh Y-P, Sheng M, Smiga S, et al. Tbr1 regulates differentiation of the preplate and layer 6. Neuron 2001; 29: 353-66.

123. Hicks TP, Lee BB, Vidyasagar TR. The responses of cells in macaque lateral geniculate nucleus to sinusoidal gratings. J Physiol 1983; 337 : 183-200.

124. Holländer H, Vanegas H. Identification of pericellular baskets in the cat striate cortex: light and electron microscopic observations after uptake of horseradish peroxidase. J Neurocytol 1981; 10: 577-87.
125. Hornung JP, Garey LJ. A direct pathway from thalamus to visual callosal neurons in the cat. Exp Brain Res 1980; 38: 121-3.

126. Hornung JP, Garey LJ. The thalamic projection to cat visual cortex: ultrastructure of neurons identified by Golgi impregnation or retrograde horseradish peroxidase transport. Neuroscience 1981; 6: 1053-68.

127. Horton JC. Cytochrome oxidase patches: a new cytoarchitectonic feature of monkey visual cortex. Phil Trans R Soc Lond B 1984; 304: 199-253.

128. Horton JC, Hedley-Whyte ET. Mapping of cytochrome oxidase patches and ocular dominance columns in human visual cortex. Phil Trans Roy Soc Lond B 1984; 304: 255-72.

129. Horton JC, Hocking DR. Effect of early monocular enucleation upon ocular dominance columns and cytochrome oxidase activity in monkey and human visual cortex. Vis Neurosci 1998; 15: 289-303.

130. Horton JC, Hubel DH. Regular patchy distribution of cytochrome oxidase staining in primary visual cortex of macaque monkey. Nature 1981 292: 762-4.

131. Hubel DH, Wiesel TN. Receptive fields, binocular interaction and functional architecture in the cat's visual cortex. J Physiol 1962; 160: 106-54

132. Hubel DH, Wiesel TN. Receptive fields and functional architecture of monkey striate cortex. J Physiol 1968; 195: 215-43.

133. Hubel DH, Wiesel TN. Anatomical demonstration of columns in the monkey striate cortex. Nature 1969; 221: 747-50.

134. Hubel DH, Wiesel TN. Laminar and columnar distribution of geniculo-cortical fibers in the macaque monkey. J Comp Neurol 1972; 146: 421-50.

135. Hubel DH. Wiesel TN. Functional architecture of macaque monkey visual cortex. Proc Roy Soc Lond B 1977; 198: 1-59.

136. Humphrey AL, Hendrikson AE. Background and stimulus-induced patterns of high metabolic activity in the visual cortex (area 17) of the squirrel monkey and macaque monkey. J Neurosci 1983; 3: 345-58.

137. Humphrey AL, Sur M, Ulrich DJ, Sherman SM. Projection patterns of individual $\mathrm{X}$-and $\mathrm{Y}$-cell axons from the lateral geniculate nucleus to cortical area 17 in the cat. J Comp Neurol 1985a; 233: 159-89.

138. Humphrey AL, Sur M, Ulrich DJ, Sherman SM. Termination patterns of individual $\mathrm{X}$-and $\mathrm{Y}$-cell axons in the visual cortex of the cat: projections to area 18 , to the $17 / 18$ border region, and to both areas 17 and 18 . J Comp Neurol 1985b; 233: 190-212.

139. Huntley GW, Vickers JC, Morrison JH. Cellular and synaptic localization of NMDA and non-NMDA receptor subunits in neocortex: organizational features related to cortical circuitry, function and disease. $\mathrm{J}$ Neurophysiol 1994; 17: 536-43

140. Imig TJ, Reale RA, Brugge JF. The auditory cortex. Patterns of corticocortical projections related to physiological maps in the cat. In Woolsey $\mathrm{CN}$, ed. Cortical sensory organization. Vol. 3. Multiple auditory areas. Clifton, New Jersey: Ed. Humana Press; 1982, p. 1-41.

141. Innocenti GM. Adult and neonatal characteristics of the callosal zone at the boundary between areas 17 and 18 in the cat. In Russell IS, van Hof MW, Berlucchi G, eds. Structure and function of cerebral commissures. London: Ed. MacMillan Press; 1979. p. 244-58.

142. Innocenti GM. General organization of callosal connections in the cerebral cortex. In Jones EG, Peters A, eds. Cerebral cortex. Vol. 5. Sensory-motor areas and aspects of cortical connectivity. New York: Ed. Plenum Press; 1986. p. 291-354.

143. Jacobson S, Trojanowski JQ. Corticothalamic neurons and thalamocortical terminal fields: an investigation in rat using horseradish peroxidase and autoradiography. Brain Res 1975; 85: 385-401.

144. Jasper HH. Functional properties of the thalamic reticular system. In Delafresnaye JF, ed. Brain mechanisms and consciousness. Oxford: Ed. Blackwell 1954. p. 374-95.

145. Jensen KF, Killackey HP. Terminal arbors of axons projecting to the somatosensory cortex of the adult rat. I. The normal morphology of specific thalamocortical afferents. J Neurosci 1987; 7: 3529-43.

146. Jerison HJ. Fossil brains and the evolution of neocortex. In Finlay BL, Innocenti $\mathrm{G}$, Scheich $\mathrm{H}$, eds. The neocortex. Ontogeny and phylogeny. New York: Ed. Plenum Press; 1991. p. 5-19.

147. Johnston JB. The telencephalon of selachians. J Comp Neurol 1911; 21: 1-113.

148. Jones EG. Varieties and distribution of non-pyramidal cells in the somatic sensory cortex of the squirrel monkey. J Comp Neurol 1975; 160: 205-68.

149. Jones EG. Laminar distribution of cortical efferent cells. In Peters A Jones EG, eds. Cerebral cortex. Vol. 1. Cellular components of the cerebral cortex. New York: Ed. Plenum Press; 1984. p. 521-53.

150. Jones EG, Hendry SHC. Basket cells. In Peters A, Jones EG, eds. Cerebral cortex. Vol. 1. Cellular components of the cerebral cortex. New York: Ed. Plenum Press; 1984. p. 309-36

151. Jones EG, Powell TPS. Electron microscopy of the somatic sensory cortex of the cat: cell types and synaptic organization. Phil Trans Roy Soc Lond B 1970; 257: 1-11.

152. Jones EG, Wise SP. Size, laminar and columnar distribution of efferent cells in the sensory-cortex of primates. J Comp Neurol 1977; 175: 391-438.

153. Kaas JH. The evolution of isocortex. Brain Behav Evol 1995; 46: 187-96. 
154. Kaplan E, Shapley RM. X and Y cells in the lateral geniculate nucleus of macaque monkeys. J Physiol 1982; 330: 125-43.

155. Karten HJ. Evolutionary developmental biology meets the brain: the origin of mammalian cortex. Proc Natl Acad Sci U S A 1997; 94: 2800-4.

156. Katz LC, Burkhalter A, Dreyer WJ. Fluorescent latex microspheres as a retrograde neuronal marker for in vivo and in vitro studies of visual cortex. Nature 1984; 310: 498-500.

157. Kaufmann WE, Moser HW. Dendritic anomalies in disorders associated with mental retardation. Cereb Cortex 2000; 10: 981-91.

158. Keller A, Asanuma H. Synaptic relationships involving local axon collaterals of pyramidal neurons in the cat motor cortex. J Comp Neurol 1993; 336: 229-42

159. Kelly JP, van Essen DC. Cell structure and function in the visual cortex of the cat. J Physiol 1974; 238: 515-47.

160. Kennedy C, des Rosiers M, Sokoloff L, Reivich M, Jehle J. The ocular dominance columns of the striate cortex as studied by the deoxyglucose method for measurement of local cerebral glucose utilization. Trans Am Neurol Ass 1975; 100: 74-7.

161. Kisvárday ZF, Beaulieu C, Eysel UT. Network of GABAergic large basket cells in cat visual cortex (area 18): implication for lateral inhibition. J Comp Neurol 1993; 327: 398-415.

162. Kisvárday ZF, Cowey A, Somogyi P. Synaptic relationships of a type of GABA-immunoreactive neuron (clutch cell), spiny stellate cells and lateral geniculate nucleus afferents in layer IVc of the monkey striate cortex. Neuroscience 1986; 19: 741-61.

163. Kisvárday ZF, Martin KAC, Freund TF, Maglóczky Z, Whitteridge D, Somogyi P. Synaptic targets of HRP-filled layer III pyramidal cells in the cat striate cortex. Exp Brain Res 1986; 64: 541-52.

164. Kisvárday ZF, Martin KAC, Whitteridge D, Somogyi P. Synaptic connections of intracellularly filled clutch cells, a type of small basket cell in the visual cortex of the cat. J Comp Neurol 1985; 241: 111-37.

165. Kornack DR, Rakic P. Cell proliferation without neurogenesis in adult primate neocortex. Science 2001; 294: 2127-30

166. Kritzer M, Cowey A, Somogyi P. Patterns of inter-and intralaminar GABAergic connections distinguish striate (V1) and extrastriate (V2, V4) visual cortices and their functionally specialized subdivisions in the rhesus monkey. J Neurosci 1992; 12: 4545-64.

167. Law MI, Zahs KR, Stryker MP. Organization of primary visual cortex (area 17) in the ferret. J Comp Neurol 1988; 278: 157-80

168. Le Gross Clark WE, Boggon RH. On the connections of the medial cell groups of the thalamus. Brain 1933; 56: 83-98.

169. LeVay S. Synaptic patterns in the visual cortex of the cat and monkey: electron microscopy of Golgi preparations. J Comp Neurol 1973; 150: 53-86.

170. LeVay S, Connolly M, Houde J, van Essen DC. The complete pattern of ocular dominance stripes in the striate cortex and visual field of the macaque monkey. J Neurosci 1985; 5: 486-501.

171. LeVay S, Ferster D. Relay cell classes in the lateral geniculate nucleus of the cat and the effects of visual deprivation. J Comp Neurol 1977; 172: 563-84.

172. LeVay S, Gilbert CD. Laminar patterns of geniculocortical projections in the cat. Brain Res 1976; 113: 1-19.

173. LeVay S, Hubel DH, Wiesel TN. The pattern of ocular dominance columns in macaque visual cortex revealed by a reduced silver stain. J Comp Neurol 1975; 159: 559-76.

174. LeVay S, McConnell SK, Luskin MB. Functional organization of primary visual cortex in the mink (Mustela vison), and a comparison with the cat. J Comp Neurol 1987; 257: 422-41.

175. LeVay S, Stryker MP, Shatz CJ. Ocular dominance columns and their development in layer IV of the cat's visual cortex: a quantitative study. J Comp Neurol 1978; 179: 223-44.

176. LeVay S, Wiesel TN, Hubel DH. The development of ocular dominance columns in normal and visually deprived monkeys. J Comp Neurol 1980; 191: 1-51.

177. Leventhal AG. Evidence that the different classes of cells of the cat's lateral geniculate nucleus terminate in different layers of the striate cortex. Exp Brain Res 1979; 37: 349-72.

178. Lewis DA. Chandelier cells: shedding light on altered cortical circuitry in schizophrenia. Mol Psychiatry 1998; 3: 468-71.

179. Lewis DA, Lund JS. Heterogeneity of chandelier neurons in monkey neocortex: corticotropin-releasing factor and parvalbumin-immunoreactive populations. J Comp Neurol 1990; 293: 599-615.

180. Lewis WB. On the comparative structure of the cortex cerebri. Brain $1878 ; 1: 79-86$

181. Lin CS, Friedlander MJ, Sherman SM. Morphology of physiologically identified neurons in the visual cortex of the cat. Brain Res 1979; 172: 344-8

182. Livingstone MS, Hubel DH. Thalamic inputs to cytochrome oxidase-rich regions in monkey visual cortex. Proc Natl Acad Sci U S A 1982; 79: 6098-101.
183. Livingstone MS, Hubel DH. Anatomy and physiology of a color system in the primate visual cortex. J Neurosci 1984; 4: 309-56.

184. Livingstone MS, Hubel DH. Psychophysical evidence for separate channels for the perception of form, color, movement, and depth. J Neurosci 1987; 7: 3416-68.

185. Lorente de Nó R. La corteza cerebral del ratón. (Primera contribución. La corteza acústica). Trab Lab Invest Biol Univ Madrid 1922; 20: 41-78.

186. Lorente de Nó R. Studies on the structure of the cerebral cortex. II. Continuation of the study of the ammonic system. J Psychol Neurol 1934; 46: 113-77.

187. Lorente de Nó R. Cerebral cortex: architecture, intracortical connections, motor projections. In Fulton's Physiology of the Nervous System. London: Ed. Oxford University Press; 1949. p. 288-300.

188. Luhman HJ, Martínez-Millán L, Singer W. Development of horizontal intrinsic connections in cat striate cortex. Exp Brain Res 1986; 63: 443-8.

189. Luhman HJ, Singer W, Martínez-Millán L. Horizontal interactions in cat striate cortex: I anatomical substrate and postnatal development. Eur J Neurosci 1990; 2: 344-57.

190. Lund JS. Organization of neurons in the visual cortex, area 17, of the monkey (Macaca mulatta). J Comp Neurol 1973; 147: 455-96.

191. Lund JS. Spiny stellate neurons. In Peters A, Jones EG, eds. Cerebral cortex. Vol. 1. Cellular components of the cerebral cortex. New York: Ed. Plenum Press; 1984. p. 255-308.

192. Lund JS, Boothe R. Interlaminar connections and pyramidal neuron organization in the visual cortex, area 17, of the macaque monkey. J Comp Neurol 1975; 159: 305-34.

193. Lund JS, Fitzpatrick D, Humphrey AL. The striate cortex of the tree shrew. In Peters A, Jones EG, eds. Cerebral cortex. Vol. 3. Visual cortex. New York: Ed. Plenum Press; 1985. p. 157-205.

194. Lund JS, Hendrickson AE, Ogren MP, Tobin EA. Anatomical organization of primate visual cortex area VII. J Comp Neurol 1981; 202: 19-45.

195. Lund JS, Henry GH, Macqueen CL, Harvey AR. Anatomical organization of the primary visual cortex (area 17) of the cat. A comparison with area 17 of the macaque monkey. J Comp Neurol 1979; 184: 599-618.

196. Marco P, de Felipe J. Altered synaptic circuitry in the human temporal neocortex removed from epileptic patients. Exp Brain Res 1997; 114: 1-10.

197. Marco P, Sola RG, Pulido P, Alijarde MT, Sánchez A, Ramón y Cajal $\mathrm{S}$, et al. Inhibitory neurons in the human epileptogenic temporal neocortex: an immunocytochemical study. Brain 1996; 119: 1327-47.

198. Marín-Padilla M. Origin of the pericellular baskets of the pyramidal cells of the human motor cortex. Brain Res 1969; 14: 633-46.

199. Marín-Padilla M. Double origin of the pericellular baskets of the pyramidal cells of the human motor cortex: a Golgi study. Brain Res 1972; 38: 1-12.

200. Marín-Padilla M. The chandelier cell of the human visual cortex: a Golgi study. J Comp Neurol 1987; 256: 81-70.

201. Martin KAC. Neuronal circuits in cat striate cortex. In Jones EG, Peters A, eds. Cerebral cortex. Vol. 2. Functional properties of cortical cells. New York: Ed. Plenum Press; 1984. p. 241-84.

202. Martin KAC. From single cells to simple circuits in the cerebral cortex. Quart J Exp Physiol 1988; 73: 637-702.

203. Martin KAC, Whitteridge D. Form, function and intracortical projections of spiny neurons in the striate visual cortex of the cat. J Physiol London 1984; 353: 463-504

204. Mates SL, Lund JS. Developmental changes in the relationship between type 2 synapses and spiny neurons in the monkey visual cortex. J Comp Neurol 1983; 221: 98-105.

205. McConnell SK, LeVay S. Anatomical organization of the visual system of the mink, Mustela vison. J Comp Neurol 1986; 250: 109-32.

206. McGuire BA, Hornung J-P, Gilbert CD, Wiesel TN. Patterns of synaptic input to layer 4 of cat striate cortex. J Neurosci 1984; 4: 3021-33.

207. McMullen TN, Glaser EM, Tagamets M. Mosphometry of spine-free nonpyramidal neurons in rabbit auditory cortex. J Comp Neurol 1984; 222: 383-95.

208. Meyer G, Albus K. Spiny stellates as cells of origin of association fibers from area 17 to area 18 in cat's neocortex. Brain Res 1981; 210: 335-41.

209. Meyer G, Ferres-Torres R. Postnatal maturation of nonpyramidal neurons in the visual cortex of the cat. J Comp Neurol 1984; $228: 226-44$

210. Meynert TH, von Gehirne der Saugethiere. In Stricker S, ed. Handbuch der Lehre von der Geweben des Menschen und der Thiere. Vol. 2. Leipzig: Ed. Wilhelm Engelmann; 1869-1872. p. 694-808.

211. Misson JP, Austin CP, Takahashi T, Cepko CL, Caviness VS. The alignment of migrating neural cells in relation to the murine neopallial radial glial fiber system. Cereb Cortex 1991; 1: 221-9.

212. Mitzdorf U, Singer W. Prominent excitatory pathways in the cat visual cortex (A 17 and A 18): A current source density analysis of electrically evoked potentials. Exp Brain Res 1978; 33: 371-94.

213. Molnár Z. Development and evolution of thalamocortical interactions. Eur J Morphol 2000; 38: 313-20.

214. Morison RS, Dempsey EW. A study of thalamocortical relations. Am J Physiol 1942; 135: 281-92. 
215. Moruzzi G, Magoun HW. Brain stem reticular formation and activation of the EEG. EEG Clin Neurophysiol 1949; 1: 455-73.

216. Mountcastle VB. Modality and topographic properties of single neurons of cat's somatic sensory cortex. J Neurophysiol 1957; 20: 408-34

217. Mountcastle VB. An organizing principle of cerebral function: the unit module and the distributed system. In Schmitt FO, Worden FG, eds. The neurosciences. Fourth study program. Cambridge, Massachusetts: Ed. MIT Press; 1979. p. 21-42.

218. Mountcastle VB, Powell TPS. Neural mechanisms subserving cutaneous sensibility, with special reference to the role of afferent inhibition in sensory perception and discrimination. Bull Johns Hopkins Hosp 1959; 105: 201-32.

219. Mower GD, Caplan CJ, Christen WG, Duffy FH. Dark rearing prolongs physiological but not anatomical plasticity of the cat visual cortex. J Comp Neurol 1985; 235: 448-66.

220. Multani P, Myers RH, Blume HW, Schomer DL, Sotrel A. Neocortical dendritic pathology in human partial epilepsy: a quantitative Golgi study. Epilepsia 1994; 35: 728-36.

221. Naegele JR, Jhaveri S, Schneider GE. Sharpening of topographical projections and maturation of geniculocortical axon arbors in the hamster. J Comp Neurol 1988; 277: 593-607.

222. Nauta WJH, Whitlock DG. An anatomical analysis of the non-specific thalamic projection system. In Delafresnaye JF, ed. Brain mechanisms and consciousness. Oxford: Ed. Blackwell 1954. p. 81-116.

223. Northcutt G, Kaas JH. The emergence and evolution of mammalian neocortex. Trends Neurosci 1995; 18: 373-9.

224. Northcutt G, Kicliter E. Organization of the amphibian telencephalon. In Ebbesson SOE, ed. Comparative neurology of the telencephalon. New York: Ed. Plenum Press; 1980. p. 203-55.

225. Nowakowski RS, Hayes NL. New neurons: extraordinary evidence or extraordinary conclusion? Science 2000; 288: 771

226. Ogren MP, Hendrickson AE. The distribution of pulvinar terminals in visual areas 17 and 18 of the monkey. Brain Res 1977; 137: 343-50.

227. Olavarría J, van Sluyters RC. Organization and postnatal development of callosal connections in the visual cortex of the rat. J Comp Neurol 1985; 239: 1-26.

228. O'Leary JL. Structure of the area striata of the cat. J Comp Neurol 1941; 75: 131-64

229. O'Leary JL, Bishop GH. The optically excitable cortex of the rabbit. J Comp Neurol 1938; 68: 423-78

230. Otsuka R, Hasler R. Uber Aufbau und Gliederung der corticalen Sehsphare bei der Katze. Arch Psychiat Z Ges Neurol 1962; 203: 212-34.

231. Palade GE. Electron microscope observations of interneuronal and neuromuscular synapses. Anat Rec 1954; 118: 335.

232. Papez JW. Thalamic connections in hemidecorticate dog. J Comp Neurol 1938; 69: 103-20.

233. Parnavelas J. The origin and migration of cortical neurones: new vistas. Trends Neurosci 2000; 23: 126-31.

234. Patel S, Rose S, Stewart M. Training induced dendritic spine density changes are specifically related to memory formation processing in chick, Gallus domesticus. Brain Res 1988; 463: 168-73.

235. Peters A. Chandelier cells. In Peters A, Jones EG, eds. Cerebral cortex. Vol. 1. Cellular components of the cerebral cortex. New York: Ed. Plenum Press; 1984a. p. 361-80.

236. Peters A. Bipolar cells. In Peters A, Jones EG, eds. Cerebral cortex. Vol. 1. Cellular components of the cerebral cortex. New York: Ed. Plenum Press; 1984b. p. 381-407

237. Peters A, Fairén A. Smooth and sparsely-spined stellate cells in the visual cortex of the rat: a study using a combined Golgi-electron microscope technique. J Comp Neurol 1978; 181: 129-72.

238. Peters A, Feldman ML. The projections of the lateral geniculate nucleus to area 17 of the rat cerebral cortex. I. General description. J Neurocytol 1976; 5: 63-84.

239. Peters A, Feldman ML. The projections of the lateral geniculate nucleus to area 17 of the rat cerebral cortex. IV. Termination upon spiny dendrites. J Neurocytol 1977; 6: 669-89.

240. Peters A, Kaiserman-Abramof IR. The small pyramidal neuron of the rat cerebral cortex: the perikaryon, dendrites and spines. Am J Anat 1970; 127: 321-55.

241. Peters A, Kimerer LM. Bipolar neurons in rat visual cortex: a combined Golgi-electron microscope study. J Neurocytol 1981; 10: 921-46.

242. Peters A, Proskauer CC. Synaptic relationships between a multipolar stellate cell and a pyramidal neuron in the rat visual cortex. A combined Golgi-electron microscope study. J Neurocytol 1980; 9: 163-83.

243. Peters A, Proskauer CC, Feldman ML, Kimerer L. The projections of the lateral geniculate nucleus to area 17 of the rat cerebral cortex. V. Degenerating axon terminals synapsing with Golgi impregnated neurons. J Neurocytol 1979; 8: 331-57.

244. Peters A, Proskauer CC, Ribak CE. Chandelier cells in the rat visual cortex. J Comp Neurol 1982; 206: 397-416.
245. Peters A, Regidor J. A reassessment of the forms of nonpyramidal neurons in area 17 of cat visual cortex. J Comp Neurol 1981; 203: 685-716.

246. Polyak S. The vertebrate visual system. Chicago: Ed. University of Chicago Press; 1957.

247. Porter LL, White EL. Synaptic connections of callosal projection neurons in the vibrissal region of the mouse primary motor cortex: an electron microscopic/horseradish peroxidase study. J Comp Neurol 1986; 248: 573-87.

248. Rakic P. Mode of cell migration to the superficial layers of fetal monkey neocortex. J Comp Neurol 1972; 145: 61-83.

249. Rakic P. Contact regulation of neuronal migration. In Edelman GM, Thiery JP, eds. The cell in contact. New York: Ed. Wiley; 1985. p. 67-91.

250. Rakic P. Radial unit hypothesis of neocortical expansion. Novartis Found Symp 2000; 228: 30-42

251. Rall W, Segev I. Synaptic integration and excitable dendritic spine clusters: structure and function. In Lasek RJ, Black MM, eds. Intrinsic determinants of neuronal form and function. New York: Ed. Liss; 1988. p. 263-82.

252. Ramón y Cajal S. Estructura de los centros nerviosos de las aves. Rev Trim Histol Norm Patol $1888 ; 1 .^{\circ}$ de Mayo.

253. Ramón y Cajal S. Neue Darstellung vom histologischen Bau des Centralnerevensystem. Arch Anat Physiol 1893: 319-428.

254. Ramón y Cajal S. Histologie du systéme nerveux de l'homme et des vertébrés. Vol. 2. Paris: Ed. Maloine; 1911.

255. Ramón y Cajal S. Textura de la corteza cerebral del gato. Trab Lab Invest Biol 1921; 19: 113-44.

256. Rausch G, Scheich H. Dendritic spine loss and enlargement during maturation of the speech control system in the mynah bird. Neurosci Lett 1982; 29: 129-33

257. Rezak M, Benevento LA. A comparison of the organization of the projections of the dorsal lateral geniculate nucleus, the inferior pulvinar and adjacent lateral pulvinar to primary visual cortex (area 17) in the macaque monkey. Brain Res 1979; 169: 19-40.

258. Ribak CE. Spinous and sparsely-spinous stellate neurons in the visual cortex of rats contain glutamic acid decarboxylase. J Neurocytol 1978; 7: 461-78.

259. Ribak CE. Local circuitry of GABAergic basket cells in the dentate gyrus. Epilepsy Res Suppl 1992; 7: 29-47.

260. Ribak CE, Peters A. An autoradiographic study of the projections from the lateral geniculate body of the rat. Brain Res 1975; 92: 341-68.

261. Rieck RW, Carey RG. Organization of the rostral thalamus in the rat: Evidence for connections to layer I of visual cortex. J Comp Neurol 1986; 234: 137-54.

262. Rockland KS. A reticular pattern of intrinsic connections in primate area V2 (area 18). J Comp Neurol 1985; 235: 467-78.

263. Rockland KS, Lund JS. Widespread periodic intrinsic connections in the tree shrew visual cortex. Science 1982; 215: 1532-4.

264. Rockland KS, Lund JS. Intrinsic laminar lattice connections in primate visual cortex. J Comp Neurol 1983; 216: 303-18

265. Rockland KS, Lund JS, Humphrey AL. Anatomical banding of intrinsic connections in striate cortex of tree shrews (Tupaia glis). J Comp Neurol 1982; 209: 41-58.

266. Rosenquist AC, Edwards SB, Palmer LA. An autoradiographic study of the projections of the dorsal lateral geniculate nucleus and the posterior nucleus in the cat. Brain Res 1974; 80: 71-93.

267. Rubenstein JLR, Anderson S, Shi L, Miyashita-Lin E, Bulfone A, Hevner R. Genetic control of cortical regionalization and connectivity. Cereb Cortex 1999; 9: 524-32

268. Rubenstein JLR, Rakic P. Genetic control of cortical development. Cereb Cortex 1999; 9: 521-3.

269. Ruiz-Marcos A, Valverde F. Dynamic architecture of the visual cortex. Brain Res 1970; 19: 25-39.

270. Salas M. Effects of early undernutrition on dendritic spines of cortical pyramidal cells in the rat. Dev Neurosci 1980; 3: 109-17.

271. Sanides D. Commissural connections of the visual cortex of the cat. In Russell IS, van Hof MW, Berlucchi G, eds. Structure and function of cerebral commissures. London: Ed. MacMillan Press; 1979. p. 236-43.

272. Sanides F. Functional architecture of the motor and sensory cortices in primates in the light of a new concept of neocortex evolution. In Noback CR, Montagna W, eds. The Primate Brain. New York: Ed. Appleton Century Crofts; 1970. p. 137-208.

273. Sawaguchi T, Kubota K. A hypothesis on the primitive neocortex evolution: column-multiplication hypothesis. Intern J Neurosci 1986; 30: 57-64.

274. Schiller PH, Malpeli JG. Functional specificity of lateral geniculate nucleus laminae of the rhesus monkey. J Neurophysiol 1978; 41: 788-96.

275. Schober W, Winkelmann E. Die geniculo-korticale Projection bei Albinoratten. J Hirnforsch 1977; 18: 1-20.

276. Segal M, Andersen P. Dendritic spines shaped by synaptic activity. Curr Opin Neurobiol 2000; 10: 582-6.

277. Selemon LD, Goldman-Rakic PS. Common cortical and subcortical targets of the dorsolateral prefrontal and posterior parietal cortices in 
the Rhesus monkey: evidence for a distributed neural network subserving spatially guided behavior. J Neurosci 1988; 8: 4049-68.

278. Shapley RM, Kaplan E, Soodak R. Spatial summation and contrast sensitivity of $\mathrm{X}$ and $\mathrm{Y}$ cells in the lateral geniculate nucleus of the macaque. Nature 1981; 292: 543-5.

279. Shatz CJ. Impulse activity and the patterning of connections during CNS development. Neuron 1990; 5: 745-56.

280. Shatz CJ, Lindström S, Wiesel TN. The distribution of afferents representing the right and left eyes in cat's visual cortex. Brain Res 1977; 131: $103-16$

281. Shatz CJ, Stryker MP. Ocular dominance in layer IV of the cat's visual cortex and the effects of monocular deprivation. J Physiol 1978; 281:267-83.

282. Shepherd GM, Greer CA. The dendritic spine: adaptations of structure and function for different types of synaptic integration. In Lasek RJ, Black MM, eds. Intrinsic determinants of neuronal form and function. New York: Ed. Liss; 1988. p. 245-62.

283. Sillito AM. Functional considerations of the operation of GABAergic inhibitory processes in the visual cortex. In Jones EG, Peters A, eds. Cerebral cortex. Vol. 2. Functional properties of cortical cells. New York: Ed. Plenum Press; 1984. p. 91-117.

284. Sokoloff L. Influence of functional activity on local cerebral glucose utilization. In Ingvar DH, Lassen N, eds. Brain work. The coupling of function, metabolism and blood flow in the brain. New York: Ed. Academic Press; 1975. p. 385-8.

285. Somogyi P. A specific axo-axonal neuron in the visual cortex of the rat. Brain Res 1977; 136: 345-50.

286. Somogyi P. The study of Golgi stained cells and of experimental degeneration under the electron microscope: a direct method for the identification in the visual cortex of three successive links in a neuron chain. Neuroscience 1978; 3: 167-80.

287. Somogyi P, Cowey A. Combined Golgi and electron microscopic study on the synapses formed by double bouquet cells in the visual cortex of the cat and monkey. J Comp Neurol 1981; 195: 547-66.

288. Somogyi P, Cowey A. Double bouquet cells. In Peters A, Jones EG, eds. Cerebral cortex. Vol. 1. Cellular components of the cerebral cortex. New York: Ed. Plenum Press; 1984. p. 337-60.

289. Somogyi P, Freund TF, Cowey A. The axo-axonic interneuron in the cerebral cortex of the rat, cat and monkey. Neuroscience 1982; 7: 2577-609.

290. Somogyi P, Freund TF, Hodgson AJ, Somogyi J, Beroukas D, Chubb IW. Identified axo-axonic cells are immunoreactive for GABA in the hippocampus and visual cortex of cats. Brain Res 1985; 332: 143-9.

291. Somogyi P, Hodgson AJ, Smith AD. An approach to tracing neuron networks in the cerebral cortex and basal ganglia. Combination of Golgi staining, retrograde transport of horseradish peroxidase and anterograde degeneration of synaptic boutons in the same material. Neuroscience 1979; 4: 1805-52.

292. Somogyi P, Kisvárday ZF, Martin KAC, Whitteridge D. Synaptic connections of morphologically identified and physiologically characterized large basket cells in the striate cortex of the cat. Neuroscience 1983; 10: 261-94.

293. Soriano E, Martínez A, Fariñas I, Frotscher M. Chandelier cells in the hippocampal formation of the rat: the entorhinal area and subicular complex. J Comp Neurol 1993; 337: 151-67.

294. Stone J, Dreher B, Leventhal A. Hierarchical and parallel mechanisms in the organization of the visual cortex. Brain Res Rev 1979; 1: 345-94.

295. Streit P. Glutamate and aspartate as transmitter candidates for systems of the cerebral cortex. In Jones EG, Peters A, eds. Cerebral cortex. Vol. 2. Functional properties of cortical cells. New York: Ed. Plenum Press; 1984. p. 119-43.

296. Supèr H, del Río JA, Martínez A, Pérez Sust P, Soriano E. Disruption of neuronal migration and radial glia in the developing cerebral cortex following ablation of Cajal-Retzius cells. Cereb Cortex 2000; 10: 602-13.

297. Supèr H, Martínez A, del Río JA, Soriano E. Involvement of distinct pioneer neurons in the formation of layer-specific connections in the hippocampus. J Neurosci 1998; 18: 4616-26.

298. Supèr H, Uylings HBM. The early differentiation of the neocortex: a hypothesis on neocortical evolution. Cereb Cortex 2001; 11: 1101-9.

299. Sur M, Angelucci A, Sharma J. Rewiring cortex: the role of patterned activity in development and plasticity of neocortical circuits. J Neurobiol 1999; 41: 33-43.

300. Swindale NV. Dendritic spines only connect. Trends Neurosci 1981; 4: 240-1.

301. Szentágothai J. Architecture of the cerebral cortex. In Jasper HH, Ward AA, Pope A, eds. Basic mechanisms of the epilepsies. Boston: Ed. Little Brown; 1969. p. 13-28.

302. Szentágothai J. The 'module concept' in cerebral cortex architecture. Brain Res 1975; 95: 475-96

303. Szentágothai J. The neuron network of the cerebral cortex: A functional interpretation. Proc Roy Soc Lond B 1978; 201: 219-48.

304. Szentágothai J. Local neuron circuits of the neocortex. In Schmitt FO,
Worden FG, eds. The neuroscience fourth study program. Cambridge, Massachusetts: Ed. MIT Press; 1979. p. 399-415.

305. Szentágothai J, Arbib MA. Conceptual models of neural organization. Neurosci Res Prog Bull 1974; 12: 307-510.

306. Tamamaki N, Fujimori E, Takauji R. Origin and route of tangentially migrating neurons in the developing neocortical intermediate zone. J Neurosci 1997; 17: 8313-23.

307. Ten Donkelaar HJ. Reptiles. In Nieuwnhuys R, Ten Donkelaar HJ, Nicholson C, eds. The central nervous system of vertebrates. Vol. 2. Berlin: Ed. Springer; 1998. p. 1315-524.

308. Tieman SB, Tumosa N. $\left[{ }^{14} \mathrm{C}\right] 2$-deoxyglucose demonstration of the organization of ocular dominance in areas 17 and 18 of the normal cat. Brain Res 1983; 267: 35-46.

309. Tigges J, Tigges M, Peracchio AA. Complementary laminar terminations of afferents to area 17 originating in area 18 and in the lateral geniculate nucleus in squirrel monkey. J Comp Neurol 1977; 176: 87-100.

310. Valverde F. Apical dendritic spines of the visual cortex and light deprivation in the mouse. Exp Brain Res 1967; 3: 337-52.

311. Valverde F. Structural changes in the area striata of the mouse after enucleation. Exp Brain Res 1968; 5: 274-92.

312. Valverde F. Dendritic spines in the visual cortex of the mouse: introduction to a mathematical model. Exp Brain Res 1969; 8: 269-83.

313. Valverde F. The Golgi method. A tool for comparative structural analyses. In Nauta WJH, Ebbesson SOE, eds. Contemporary research methods in neuroanatomy. Berlin: Ed. Springer; 1970. p. 12-31.

314. Valverde F. Short axon neuronal subsystems in the visual cortex of the monkey. Intern J Neurosci 1971a; 1: 181-97.

315. Valverde F. Rate and extent of recovery from dark rearing in the visual cortex of the mouse. Brain Res 1971b; 33: 1-11

316. Valverde F. Aspects of cortical organization related to the geometry of neurons with intra-cortical axons. J Neurocytol 1976; 5: 509-29.

317. Valverde F. The organization of area 18 in the monkey. A Golgi study. Anat Embryol 1978; 154: 305-34

318. Valverde F. A comparative approach to neocortical organization based on the study of the brain of the hedgehog (Erinaceus europaeus). In Grisolía S, Guerri C, Samson F, Norton, Reinoso-Suárez F, eds. Ramón y Cajal's contribution to the neuroscience. Amsterdam: Ed. Elsevier; 1983. p. $149-70$.

319. Valverde $\mathrm{F}$. The organizing principles of the primary visual cortex in the monkey. In Peters A, Jones EG, eds. Cerebral cortex. Vol. 3. Visual cortex. New York: Ed. Plenum Press; 1985. p. 207-57.

320. Valverde F. Intrinsic neocortical organization: Some comparative aspects. Neuroscience 1986; 18: 1-23.

321. Valverde F. Competition for the sake of diversity. Behav Brain Sci 1988; 11: 102-3.

322. Valverde F. Aspects of phylogenetic variability of neocortical intrinsic organization. In Finlay BL, Innocenti G, Scheich H, eds. The neocortex. Ontogeny and phylogeny. New York: Ed. Plenum Press; 1990. p. 87-102.

323. Valverde F. The organization of the striate cortex. In Dreher B, Robinson SR, eds. Vision and visual dysfunction. Vol. 3. Neuroanatomy of the visual pathways and their development. Basingstoke: Ed. MacMillan Press; 1991. p. 235-77.

324. Valverde F. The rapid Golgi technique for staining CNS neurons: light microscopy. Neurosci Protoc 1993; 93-050-01-01.

325. Valverde F. Golgi atlas of the postnatal mouse brain. Wien: Ed. Springer; 1998.

326. Valverde F, de Carlos JA, López-Mascaraque L, Doñate-Oliver F. Neocortical layers I and II of the hedgehog (Erinaceus europaeus). II. Thalamo-cortical connections. Anat Embryol 1986; 175: 167-79.

327. Valverde F, Facal-Valverde MV. Neocortical layers I and II of the hedgehog (Erinaceus europaeus). I. Intrinsic organization. Anat Embryol 1986; 173: 413-30.

328. Valverde F, Facal-Valverde MV, Santacana M, Heredia M. Development and differentiation of early generated cells of sublayer VIb in the somatosensory cortex of the rat. A combined Golgi and autoradiographic study. J Comp Neurol 1989; 290: 118-40.

329. Valverde F, López-Mascaraque L, de Carlos JA. Structure of the nucleus olfactorius anterior in the hedgehog (Erinaceus europaeus). J Comp Neurol 1989; 279: 581-600.

330. Valverde F, Ruiz-Marcos A. Dendritic spines in the visual cortex of the mouse: introduction to a mathematical model. Exp Brain Res 1969; 8: 269-83.

331. Vogt BA, Peters A. Form and distribution of neurons in rat cingulate cortex: areas 32, 24 and 29. J Comp Neurol 1981; 195: 603-25.

332. Vogt C, Vogt O. Allgemeinere Ergebnisse unserer Hirnforschung. J Psychol Neurol 1919; 25: 279-462.

333. Weber JT, Huerta MF, Kaas JH, Harting JK. The projections of the lateral geniculate nucleus of the squirrel monkey: studies of the interlaminar zones and the S layers. J Comp Neurol 1983; 213: 135-45. 
334. Welker C. Receptive fields of barrels in the somatosensory neocortex of the rat. J Comp Neurol 1976; 166: 173-90.

335. Welker C, Woolsey TA. Structure of layer IV in the somatosensory neocortex of the rat: description and comparison with the mouse. J Comp Neurol 1974; 158: 437-54.

336. White EL. Identified neurons in mouse SmI cortex, which are postsynaptic to thalamocortical axon terminals: a combined Golgielectron microscope and degeneration study. J Comp Neurol 1978; 181: 627-62.

337. White EL. Thalamocortical synaptic relations: a review with emphasis on the projections of specific thalamic nuclei to the primary sensory areas of the neocortex. Brain Res Rev 1979; 1: 275-311.

338. White EL. Cortical circuits. Synaptic organization of the cerebral cortex, structure, function, and theory. Boston: Ed. Birkhäuser; 1989.

339. White EL, Czeiger D. Synapses made by axons of callosal projection neurons in mouse: somatosensory cortex, emphasis on intrinsic connections J Comp Neurol 1991; 303: 233-44.

340. White EL, DeAmicis R. Afferent and efferent projections of the region in mouse SmI cortex which contains the posteromedial barrel subfield. J Comp Neurol 1977; 175: 455-81.

341. White EL, Hersch SM. Thalamocortical synapses of pyramidal cells which project from SmI to MsI cortex in the mouse. J Comp Neurol 1981; 198: 167-81.

342. White EL, Hersch SM. A quantitative study of thalamocortical and other synapses involving the apical dendrites of corticothalamic projection cells in mouse SmI cortex. J Neurocytol 1982; 11: 137-57.

343. White EL, Keller A. Intrinsic circuitry involving the local axonal collaterals of corticothalamic projection cells in mouse SmI cortex. J Comp Neurol 1987; 262: 13-26.

344. Wiesel TN, Hubel DH. Extent of recovery from the effects of visual deprivation in kittens. J Neurophysiol 1965; 28: 1060-72.

345. Wilson ME, Cragg BG. Projection from the lateral geniculate nucleus in the cat and monkey. J Anat London 1967; 101: 677-92.

346. Winfield DA, Powell TPS. The termination of thalamo-cortical fibers in the visual cortex of the cat. J Neurocytol 1976; 5: 269-81.

347. Winfield DA, Powell TPS. Laminar cell counts and geniculocortical boutons in area 17 of cat and monkey. Brain Res 1983; 277: 223-9.

348. Winfield DA, Rivera-Domínguez M, Powell TPS. The termination of geniculocortical fibers in area 17 of the visual cortex in the macaque monkey. Brain Res 1982; 231: 19-32.

349. Wise SP, Jones EG. The organization and postnatal development of the

\section{ESTRUCTURA DE LA CORTEZA CEREBRAL. ORGANIZACIÓN INTRÍNSECA Y ANÁLISIS COMPARATIVO DEL NEOCÓRTEX}

Resumen. Se describe el estado actual de nuestros conocimientos sobre la organización intrínseca del neocórtex basado en estudios realizados con el método de Golgi en varios mamíferos. Hemos revisado aspectos generales de las fibras aferentes corticales específicas, describiendo su terminación en la capa IV y haciendo una comparación entre insectívoros, roedores, carnívoros y primates. Los componentes neuronales de la corteza cerebral se han dividido en dos grandes apartados: en el primero se describen las características de las células piramidales, que representan aproximadamente el $70 \%$ de toda la población. En un segundo grupo pasamos revista a las células intrínsecas, células de tipo II de Golgi, o neuronas de axon corto; describimos las distintas variedades celulares, su morfología dendrítica y axonal, y realizamos un estudio comparativo entre las distintas especies. En este grupo se revisa con especial interés el aspecto morfológico de las células estrelladas con espinas, detallando algunos conceptos de conectividad que parecen ser únicos para determinadas especies. Hemos revisado los circuitos intrínsecos de la corteza cerebral, con especial interés sobre las conexiones interlaminares, distribución de plexos dendríticos y establecimiento de contactos sinápticos de tipo excitatorio e inhibitorio. Por último, hemos revisado nuestros conocimientos sobre la organización funcional de la corteza cerebral basados en el concepto de organización modular, concluyendo que el neocórtex aparece uniforme a un nivel de organización elemental, pero muestra notables diferencias de estructura celular y conexiones cuando se comparan distintas especies de mamíferos. [REV NEUROL 2002; 34: 758-80]

Palabras clave. Aferentes corticales. Células intrínsecas. Células piramidales. Corteza cerebral. Organización modular. commissural projections in the rat somatic sensory cortex. J Comp Neurol 1976; 168: 313-44

350. Wong-Riley MTT. Endogenous peroxidatic activity in brain stem neurons as demonstrated by their staining with diaminobenzidine in normal squirrel monkey. Brain Res 1976; 108: 257-77.

351. Wong-Riley MTT. Changes in the visual system of monocularly sutured or enucleated cats demonstrable with cytochrome oxidase histochemistry. Brain Res 1979; 171: 11-28.

352. Wong-Riley MTT. Primate visual cortex. Dynamic metabolic organization and plasticity revealed by cytochrome oxidase. In Peters A, Rockland KS, eds. Cerebral cortex. Vol. 10. Primary visual cortex in primates. New York: Ed. Plenum Press; 1994. p. 141-200.

353. Wong-Riley MTT, Merzenich MM, Leake PA. Changes in endogenous enzymatic reactivity to DAB induced by neuronal inactivity. Brain Res 1978; 141: 185-92.

354. Wong-Riley MTT, Tripathi SC, Trusk TC, Hoppe DA. Effects of retinal impulse blockade on cytochrome oxidase-rich zones in the macaque striate cortex: I. Quantitative electron-microscopic (EM) analysis of neurones. Vis Neurosci 1989a; 2: 483-97.

355. Wong-Riley MTT, Trusk TC, Tripathi SC, Hoppe DA. Effects of retinal impulse blockade on cytochrome oxidase-rich zones in the macaque striate cortex: II. Quantitative electron-microscopic (EM) analysis of neuropil. Vis Neurosci 1989b; 2: 499-514.

356. Woolsey CN. Organization of cortical auditory system: a review and a synthesis. In Rasmussen GL, Windle WF, eds. Neural mechanisms of the auditory and vestibular systems. Springfield: Ed. Ch Thomas; 1960. p. 165-80.

357. Woolsey TA, Dierker ML, Wann DF. Mouse SmI cortex: qualitative and quantitative classification of Golgi-impregnated barrel neurons. Proc Natl Acad Sci U S A 1975; 72: 2165-9.

358. Woolsey TA, van der Loos $\mathrm{H}$. The structural organization of layer IV in the somatosensory region (SI) of mouse cerebral cortex. Brain Res 1970; 17: 205-42.

359. Yuste R, Bonhoeffer T. Morphological changes in dendritic spines associated with long-term synaptic plasticity. Ann Rev Neurosci 2001; 24: 1071-89.

360. Záborsky L, Wolff JR. Distribution patterns and individual variations of callosal connections in the albino rat. Anat Embryol 1982; 165: 213-32.

361. Zhu Y, Li H-S, Zhou L, Wu JY, Rao Y. Cellular and molecular guidance of GABAergic neuronal migration from an extracortical origin to the neocortex. Neuron 1999; 23: 473-85.

\section{ESTRUTURA DO CÓRTEX CEREBRAL. ORGANIZAÇÃO INTRÍNSECA E ANÁLISE COMPARATIVA DO NEOCÓRTEX}

Resumo. Descreve-se o estado actual dos nossos conhecimentos sobre a organização intrínseca do neocórtex, com base em estudos realizados com o método de Golgi em diversos mamíferos. Foram revistos aspectos gerais das fibras aferentes corticais específicas, descrevendo a sua terminação no revestimento IV e fazendo uma comparação entre insectívoros, roedores, carnívoros e primatas. Os componentes neuronais do córtex cerebral foram divididos em dois grandes capítulos: no primeiro descrevem-se as características das células piramidais, que representam aproximadamente $70 \%$ de toda a população. No segundo grupo passamos revista às células intrínsecas, células tipo II de Golgi, ou neurónios de axónio curto, descrevendo as variedades celulares distintas, a sua morfologia dendrítica e axonal e realizando um estudo comparativo entre as espécies distintas. Neste grupo é revisto com especial interesse o aspecto morfológico das células estreladas com espinhas, detalhando alguns conceitos de conectividade que parecem ser únicos para determinadas espécies. Foram revistos os circuitos intrínsecos do córtex cerebral com especial interesse nas conexões inter-laminares, distribuição de plexos dendríticos e estabelecimento de contactos sinápticos de tipo excitatório e inibitório. Por último, foram revistos os nossos conhecimentos sobre a organização funcional do córtex cerebral, com base no conceito de organização modular, concluindo que o neocórtex aparece uniforme a um nível de organização elementar, mostrando no entanto, notáveis diferenças na estrutura celular e nas conexões quando se comparam espécies distintas de mamíferos. [REV NEUROL 2002; 34: 758-80]

Palavras chave. Aferentes corticais. Células intrínsecas. Células piramidais. Córtex cerebral. Organização modular. 